\title{
Expansin-controlled cell wall stiffness regulates root growth in Arabidopsis
}

Marketa Samalova ${ }^{1}$, Kareem Elsayad ${ }^{2}$, Alesia Melnikava ${ }^{1,7}$, Alexis Peaucelle ${ }^{3}$, Evelina Gahurova $^{1,7}$, Jaromir Gumulec ${ }^{4}$, Ioannis Spyroglou1, Elena V. Zemlyanskaya ${ }^{5,6}$, Elena V. Ubogoeva $^{5}$, and Jan Hejatko ${ }^{1,7, *}$

1 Central European Institute of Technology (CEITEC MU), Masaryk University, Brno, Czech Republic

${ }^{2}$ Advanced Microscopy, Vienna Biocenter Core Facilities (VBCF), Vienna, Austria

${ }^{3}$ INRAE, Versailles-Grignon, France

${ }^{4}$ Department of Pathological Physiology, Faculty of Medicine, Masaryk University, Brno, Czech Republic

${ }^{5}$ Department of Natural Sciences, Novosibirsk State University, Novosibirsk, Russia

6 Institute of Cytology and Genetics, Siberian Branch of Russian Academy of Sciences, Novosibirsk, Russia

${ }^{7}$ National Centre for Biotechnological Research, Faculty of Science, Masaryk University, Brno, Czech Republic

*For correspondence: jan.hejatko@ceitec.muni.cz

\begin{abstract}
Expansins facilitate cell expansion via mediating $\mathrm{pH}$-dependent cell wall $(\mathrm{CW})$ loosening. However, the role of expansins in the control of biomechanical CW properties in the tissue and organ context remains elusive. We determined hormonal responsiveness and specificity of expression and localization of expansins predicted to be direct targets of cytokinin signalling. We found EXPA1 homogenously distributed throughout the CW of columella/ lateral root cap, while EXPA10 and EXPA14 localized predominantly at the three-cell boundaries of epidermis/cortex in various root zones. Cell type-specific localization of EXPA15 overlaps with higher CW stiffness measured via Brillouin light scattering microscopy. As indicated by both Brillouin frequency shift and AFM-measured Young's modulus, EXPA1 overexpression upregulated CW stiffness, associated with shortening of the root apical meristem and root growth arrest. We propose that root growth in Arabidopsis requires delicate orchestration of biomechanical CW properties via tight regulation of various expansins' localization to specific cell types and extracellular domains.
\end{abstract}

Keywords: expansin, cytokinins, cell wall, root apical meristem, Arabidopsis, biomechanics, Brillouin light scattering, atomic force microscopy 


\section{INTRODUCTION}

The cell wall $(\mathrm{CW})$ is a fundamental component of plant cells that shapes the plant body, plays key roles in development and growth of organs, movement of solutes and nutrients and protects plants from the environment. CW developmental importance is also recognised in the control of cell differentiation and intercellular communication (Wolf et al., 2012). CWs provide the strength, yet they have the ability to expand. Recent studies of growth regulatory networks suggest that the turgor-driven cell expansion is the result of a fine-tuned balance between wall relaxation and stiffening linked by a mechanosensing feedback loop (Braybrook and Jönsson, 2016; Sassi and Trass, 2015; Willis et al., 2016). These regulatory networks comprise transcription factors and plant hormones and allow tight control over equilibrium between cell division and differentiation, a process fundamental for growth and development of individual organs in any multicellular organism.

The primary CW consists predominantly of the polysaccharides, cellulose, hemicellulose and pectins. Cellulose microfibers provide the main load-bearing characteristics of the $\mathrm{CW}$, however, the presence of hemicellulose and pectins can alter the viscoelastic properties of the wall matrix (Cosgrove, 2018; Wolf et al., 2012). Once the final cell size is reached, a secondary CW can be deposited in specific cell types e.g. xylem tracheary elements (for review see Didi et al., 2015) to provide additional mechanical strength. Modulation of CW mechanical properties occurs through the control of biochemical composition as well as the degree and nature of linkages between the CW polysaccharides. Interestingly, wall extensibility may be controlled at limited regions, so called 'biomechanical hotspots', where cellulose-cellulose contacts are made, potentially mediated by trace amounts of xyloglucan (Cosgrove, 2014; 2018; 2018b). These relatively limited contact points between cellulose microfibrils may be key sites of a complex process allowing targeted wall expansion, the cell wall loosening.

Expansins, originally described as CW loosening agents during "acid growth" (McQueen-Mason et al., 1992), become activated during CW acidification triggered by a number of stimuli through the plasma membrane $\mathrm{H}^{+}$-ATPase proton pump (Cosgrove, 2005). Mechanistically, expansins neither possess polysaccharide hydrolytic activity nor change composition of the $\mathrm{CW}$; instead they are proposed to disrupt non-covalent bonds between cellulose and components of surrounding $\mathrm{CW}$ matrix, thus relaxing wall stresses and allowing turgor-driven expansion (McQueen-Mason et al., 1995; Cosgrove, 2005). Arabidopsis thaliana has 36 members of the expansin superfamily (Sampedro and Cosgrove, 2005) that promote CW loosening or are related to the growth of specific cells. EXPA1 (At1g69530) is known for decades from experiments with beads loaded with purified expansin that induced leaf primordia formation on the shoot apical meristem of tomato (Fleming et al., 1997). Apart from leaf organogenesis (Reinhardt et al., 1998) and vascular tissue differentiation (Cho and Kende, 1998), expansins are involved in root development and growth (Lee and Kim, 2013; Pacifici et al., 2018; Ramakrishna et al., 2019), root hair initiation (Cho and Cosgrove, 2002) and seed germination (Sanchez-Montesino, et al., 2019; Ribas et al., 2019). Interestingly, NbEXPA1 was shown to be plasmodesmata-specific and functions as a novel host factor for potyviral infection (Park et al., 2017).

The biomechanical interactions of cells with extracellular matrix have been demonstrated as an important regulator of cell fate specification in animal models (Engler et al., 2006). In plants, 
changes in the $\mathrm{CW}$ mechanics are a driving force of growth and development as predicted by a number of biomechanical models (Braybrook and Jonsson, 2016; Geitmann and Ortega, 2009; Haas et al., 2020; Hamant and Traas, 2010; Sassi and Traas, 2015). To name a few, in vivo chemical modification (demethylesterification) of homogalacturonan by pectin methyl-esterases was shown to be sufficient for the initiation of novel flower and floral organ primordia in Arabidopsis. Vice versa, inhibition of homogalacturonan demethylesterification resulted in the inhibition of normal organ formation (Peaucelle et al., 2008). Importantly, demethylesterification of homogalacturonan was shown to be associated with an increase in CW plasticity as measured via atomic force microscopy (AFM), suggesting that higher elasticity of CWs might be instructive for newly formed organ primordia (Peaucelle et al., 2011). In plants, the importance of biomechanical CW properties has been described mostly in the shoot tissues (Reinhardt et al., 1998; Pien et al., 2001; Hamant et al., 2008; Sampathkumar et al., 2014; Landrein et al., 2015; Gruel et al., 2016; Hervieux et al., 2017; Majda et al., 2017; Takatani et al., 2020). However, the biomechanical interactions associated mostly with the control of CW properties are emerging as an important mechanism guiding also root growth and development (Vermeer et al., 2014; Barbez et al., 2017; Pacifici et al., 2018; Ramakrishna et al., 2019; Hurny et al., 2020).

Phytohormones including auxins and cytokinins, are key players in growth regulation responses and are thus determinants of plant architecture and CW development. Well known is the role of auxins in the "acid growth theory" (Cleland, 1971; Hager et al., 1971), in which auxin induced extrusion of protons into the apoplast activates expansins, leading to $\mathrm{CW}$ loosening and growth. Cytokinins were described as factors controlling the equilibrium between cell division and differentiation (Dello loio et al., 2007, 2008) in the root apical meristem (RAM) by positioning the auxin minimum that triggers the developmental switch (Di Mambro et al., 2017). Recently, Pacifici et al. (2018) proposed EXPA1 as a direct target of multistep phosphorelay signalling in the cytokinin-regulated cell differentiation in the RAM.

Brillouin light scattering (BLS) is the inelastic scattering of light from inherent or stimulated high frequency acoustic vibrations in a sample, the speed of which is directly related to the elastic modulus of the material (Berne and Pecora, 2000). BLS microscopy is an all optical label-free spectroscopic technique that allows one to spatially map the so-called inelastic Brillouin frequency shift (BFS, $v_{\mathrm{B}}$ ) with near diffraction limited lateral resolution (Elsayad et al., 2019; Prevedel et al., 2019) of live cells (Scarcelli et al., 2015) and tissue (Elsayad et al., 2016). Advances in Brillouin spectrometer design over the last decade (Scarcelli and Yun, 2007) have allowed for studies of live cell and tissue biomechanics at near physiological conditions. In a typical confocal Brillouin microscope, the detector is replaced by a virtually imaged phased-array (VIPA)-based Brillouin spectrometer which acquires an image of the spectrum on the electron multiplying (EM)-CCD camera. The distance of the Brillouin peaks (in $\mathrm{GHz}$ ) from the central laser frequency is a measure of the local mechanical properties at the confocal volume. Despite probing a distinct elastic modulus in a different frequency regime, the measured BLS has been empirically found to (semilogarithmically) scale with the lower frequency stiffness defined via the Young's modulus. BFS can be expected to be higher for "stiffer" samples and smaller for "softer" cells and tissue (Andriotis et al., 2019; Gouveia et al., 2019; Scarcelli et al., 2015). The Young's modulus is typically measured by atomic force microscopy (AFM). This method is based on micrometer or nanometer tissue compressions (indentations) and was developed to measure precisely the mechanical 
properties of CWs in developing organs and across entire tissue regions (Peaucelle, 2014). The measured stiffness (resistance to deformation/ indentation) is defined by the measurement of an indentation modulus that best describes the elasticity of the scaffolding of the $\mathrm{CW}$ of the tissue. AFM can be also used to image CW surface topology at high resolution to detect individual cellulose microfibrils (app. $3 \mathrm{~nm}$ in diameter, Zhang et al., 2014) and can be carried out under water, allowing imaging of $\mathrm{CW}$ in a near-native state.

In this work, we set out to localise EXPA1 and its homologues EXPA10, EXPA14 and EXPA15 and describe the relationship between expression of expansins and the mechanical properties of the $\mathrm{CW}$ during root cell differentiation. To quantitate the changes in $\mathrm{CW}$ biomechanics, we introduce mechano-optical contrast (MOC) as a new measure of mechanical properties for various biological structures measured via Brillouin light scattering and confirm the results using more established atomic force microscopy (AFM).

\section{RESULTS}

\section{Cytokinins and auxins control EXPAs transcription in the Arabidopsis root}

For our study we selected expansins AtEXPA1 (EXPA1, At1g69530), AtEXPA10 (EXPA10, At1g26770), AtEXPA14 (EXPA14, At1g69530) and AtEXPA15 (EXPA15, At2g03090), previously suggested to be under hormonal control (Lee et al., 2007; Bhargava et al., 2013; Pacifici, et al., 2018; Ramakrishna et al., 2019).

According to published data (Zubo et al., 2017; Pacifici et al., 2018; Taniguchi et al., 2007; Xie et al., 2018), EXPA1 was supposed to be the direct target of cytokinin-responsive ARABIDOPSIS RESPONSE REGULATOR 1 (ARR1) and its homologues ARR10 and ARR12 (Figure 1A). EXPA1 responsiveness to auxin could be potentially regulated by AUXIN RESPONSE FACTOR 5 (ARF5) since the corresponding DNA affinity purification (DAP)-sequencing peaks (O'Malley et al., 2016) are located in its promoter (Figure 1B). To confirm the hormonal regulations over EXPA1, we quantified EXPA1 transcripts using reverse transcription quantitative real-time PCR (RT qPCR) in wild-type (WT) Arabidopsis seedlings treated with $5 \mu \mathrm{M}$ 6-Benzylaminopurine (BAP) and $5 \mu \mathrm{M} 1$ naphthaleneacetic acid (NAA, Figure 1C). With the cytokinin treatment, transcript levels were transiently and rather moderately (3-4 times compared to the mock-treated control) upregulated during the 4-hour time span tested; similar results were obtained using trans-zeatin (tZ, data not shown). Compared to that, EXPA1 responded more distinctly to the auxin treatment and its transcript level was increased continuously up to 5-10 fold at $4 \mathrm{~h}$. However, no increase in EXPA1 promoter activity was detected in a pEXPA1::nls:3xGFP transcriptional fusion line (Ramakrishna et al., 2019) after both cytokinin and auxin treatment (Figure 1-figure supplement 1) neither in RAM nor TZ.

Based on our in silico analysis, EXPA10, EXPA14 and EXPA15 (Figure 2-figure supplement 1) might also be direct targets of cytokinin-activated type-B ARRs. In line with that, both EXPA14 and EXPA15 were upregulated by cytokinins; nonetheless, in contrast to previous report (Pacifici et al., 2018), no positive response has been detected in case of EXPA10 (both BAP and tZ, Figure 2 and data not shown). 
Altogether, our data suggest moderate and transient EXPA1 and EXPA14 upregulation by cytokinins, stronger response was seen in case of auxin- and cytokinin-mediated upregulation of EXPA1 and EXPA15, respectively. However, no clear effect of exogenous hormone application was detectable for EXPA10.

\section{Expansins localise to the root $\mathrm{CW}$ in a specific pattern}

Previously, expansins were shown to be localised in the CW by immunogold labelling of CWs and Golgi-derived vesicles using antibody against $\alpha$-expansin (Cosgrove et al., 2002). However, so far attempts to visualise expansins in the $\mathrm{CW}$ of living plants by a translational fusion with a green fluorescent protein (GFP) failed (Pacifici et al., 2018), perhaps due to high sensitivity of GFP to the low pH environment. Therefore, we created translational fusions of EXPA1, EXPA10, EXPA14 and EXPA15 with a red fluorescent protein mCherry (Shaner et al., 2004) under the control of native promoters and confirmed their CW localisation in a highly tissue-specific manner in roots (Figures 1 and 3).

In Arabidopsis root, EXPA1 revealed the strongest expression in the columella and lateral root cap (LRC) of both the main and lateral roots (Figure 1D-G). Interestingly, the cells immediately surrounding developing lateral roots and primordia were also strongly expressing EXPA1 (Figure $1 G)$. These results were confirmed using an independent transcriptional $p E X P A 1:: n / s: 3 \times G F P$ fusion line (Ramakrishna et al., 2019) crossed into the mCherry line background (Figure $1 \mathrm{~F}$ and $1 \mathrm{G})$. Occasionally, very weak EXPA1 promoter activity was detectable in the root transition zone (TZ)/elongation zone (EZ) boundary (Figure 1 - figure supplement 2A); however, no EXPA1:mCherry was detectable there (Figure 1 - figure supplement $2 \mathrm{~B}$ ).

EXPA10 was visibly expressed in the cortex layer of the primary root from the meristematic zone up (proximally) to the first lateral roots (Figure 3A). Unlike EXPA1, EXPA10 is not expressed in the LRC. Interestingly, in contrast to a rather homogenous distribution of EXPA1 throughout the $\mathrm{CW}$ surrounding the LRC/columella cells, we observed distinct "spotty" localisation of EXPA10 dominantly in the cortex/endodermis and cortex/epidermis three-cell boundaries that was particularly visible on the cross-sections of the roots (Figure 3A, insets I.-III.). This kind of unequal distribution of EXPA10 in the three-cell boundaries was occasionally detectable also in the longitudinal plane view of the root cortex cell files. Here, the positions of EXPA10 localization maxima do not seem to overlap with cellulose deposition as detected using calcofluor white staining of fixed roots (Figure 3 - figure supplement 1 , white arrows). In the lateral roots, the EXPA10:mCherry fusion localised predominantly in the epidermis and cortex layers of the transition/elongation zones (Figure 3B and inset IV.).

EXPA14:mCherry fusion localises in the cortex layer of the RAM up to the TZ/EZ boundary, proximally from which the signal disappears (Figures 3C, D). The distinct pattern of strong accumulation of the protein in the apoplastic space at the boundary of three cells (insets for Figure $3 \mathrm{C}$ and $3 \mathrm{E}$, Figure 3 -figure supplement $2 \mathrm{~A}$ ) resembles the one observed for EXPA10:mCherry fusion. In the lateral roots, EXPA14 is also strongly expressed in the transition/elongation zones (Figure $3 \mathrm{E}$ ). However, in contrast to the situation in the main root, in the lateral root EXPA14 locates not only to cortex, but also to the epidermal cell layers (Figure 3E inset II.). 
EXPA15:mCherry is localised in the epidermis of RAM (Figure 3F) and emerging lateral roots (Figure 3G, Figure 3 - figure supplement 2B) in a relatively uniform pattern; however, the "spotty" pattern at three-cell boundary was apparent in the more internal cortex/endodermis. Proximally from the meristematic zone, EXPA15 re-localises into deeper (vasculature) layers, again revealing rather homogenous distribution (Figure $3 \mathrm{H}$ insets I.-II.).

Worth of note, in contrast to homogenously distributed EXPA1 and (partially) EXPA15, EXPA10 and EXPA14 seem to be localized dominantly in the longer (parallel with the longitudinal root axis) walls of elongated cells, particularly in the RAM of the main root (Figure 3 - figure supplement 3 ).

To confirm the extracellular localisation, we activated the (naturally very weak) expression of EXPA1:Cherry in all plant tissues (Figure 4) using the dexamethasone (Dex) inducible system pOp6/LhGR (Craft et al., 2005; Samalova et al., 2005; Samalova et al., 2019). After both long (7 days) and short $(24 \mathrm{~h})$ Dex induction, the fusion protein accumulated in the cell periphery/apoplastic space in roots but was also visible in the transit through the secretory pathway from the endoplasmic reticulum (ER) to the CW. However, since the resolution of a confocal microscope does not allow to distinguish between $\mathrm{CW}$ and plasma membrane localisation, we treated the roots with $10 \%$ sorbitol to allow for plasmolysis. Figure $4 \mathrm{G}$ shows that unlike the plasma membrane marker (Figure 4-figure supplement 1), EXPA1:mCherry remained located at the outer edges of the cells, suggesting that EXPA1 is indeed localised in the cell wall. Importantly, the CW localization pattern we observed in case of the Dex-induced pRPS5A>GR>EXPA1:mCherry line was still resembling the homogenous distribution we observed in case of EXPA1:mCherry driven by its natural promoter in the lateral root cap tissue (compare Figures 1 and 4). This is suggesting that the CW localization pattern of EXPA1 is independent of the cell type and the level of expression.

To conclude, all assayed expansins show distinct expression and localization patterns. The differences in the localization pattern between EXPA1 revealing homogenous distribution all around the cell and the "spotty" localization of EXPA10, EXPA14 and (partially) EXPA15 implies differential roles of individual EXPAs in the control over root CW properties.

\section{Introducing mechano-optical contrast for Brillouin-based imaging of biological samples}

To investigate the biomechanical properties on the sub-cellular level we used Brillouin light scattering (BLS) microscopy. The Brillouin frequency shift $\left(v_{\mathrm{B}}\right)$ is proportional to the acoustic phonon velocity, which is in turn proportional to the square root of the high frequency longitudinal elastic modulus (M). As such, the Brillouin frequency can serve as a proxy for the mechanical properties of the sample. In particular, $M$ is closely related to the compressibility of the sample, and has empirically been observed to scale semi-logarithmically with the Young's modulus (E) as measured by AFM in diverse samples including live cells (Scarcelli et al., 2015). An exact calculation of $\mathrm{M}$ requires knowledge of the ratio $n^{2} / \rho$ where $n$ and $\rho$ are the refractive index and mass density in the probed region of the sample respectively. While it can by virtue of the LorentzLorenz (LL) relation often be assumed that $n^{2}$ will scale with $\rho$ (Zhao et al., 2011) such that explicit knowledge of the ratio $n^{2} / \rho$ at each probed region is not required, the validity of the LL-relation in complex multicomponent structures including the $\mathrm{CW}$ cannot be rigorously justified. As such, we present results in terms of a dimensionless frequency shift we term the Mechano-Optical Contrast 
(MOC), $v_{B}^{\prime}=v_{B} / v_{B}{ }^{(w)}$, where $v_{B}(w)$ is the measured BLS frequency of distilled water (Antonacci et al., 2020). As is the case for the Brillouin frequency shift, the MOC will scale as the square root of $\mathrm{M}$, with the advantage that it is independent of the probing wavelength, can correct for slight variations in temperature between measurements and allows for the more straight forward comparisons of measurements between instruments employing different probing wavelengths.

\section{EXPA1 overexpression stiffens root cell wall}

To characterize its importance in the control of biomechanical CW properties, we overexpressed EXPA1 (without any tag) and generated pRPS5A>GR>EXPA1 Dex-inducible lines (8-4 and 5-4) using the pOp6/LhGR system as above. Representative 2D Brillouin frequency shift maps (Figure $5 \mathrm{~A})$ display the BLS shift in the CW of plants overexpressing EXPA1 before and after induction. We quantified the MOC in roots (early EZ) of 7-day old Arabidopsis WT and EXPA1 overexpressing seedlings (line 8-4) grown on MS media pH 5.8 or pH 4 (Figure 5B and C, respectively) with or without Dex induction. From the technical reasons (to obtain sufficient overlap of point spread function with cell wall and hence good CW signal) and the expression profile of assayed EXPA genes (epidermis and/or cortex), we focused on the longitudinal inner epidermal CWs (epidermis/cortex boundary). The plants overexpressing EXPA1 showed a higher MOC (longitudinal elastic modulus, vide supra) for the root $\mathrm{CW}$ s on both $\mathrm{pH}$ media, suggesting that their CWs are stiffer. The pRPS5A>GR>EXPA1:mCherry lines induced on Dex also displayed higher $M O C$, however not significantly different from the non-induced plants (Figure 5 - figure supplement $1 \mathrm{~A}$ ), perhaps due to lower expression levels of the EXPA1 (Figure 5 - figure supplement 2). Importantly, we have detected increase in the MOC/CW stiffness even in response to short-term Dex-mediated EXPA1 upregulation. For the strong expression line pRPS5A>GR>EXPA1 (8-4), the statistically significant change was observed as soon as $3 \mathrm{~h}$ after EXPA1 induction (Figure 5D, E) on media at both $\mathrm{pH}$ tested (4 and 5.8). In case of a weaker expression line pRPS5A>GR>EXPA1:mCherry (1-3), the significant increase in MOC was detected later, after 6 $\mathrm{h}$ of induction and only on the media with $\mathrm{pH} 4.0$ (Figure 5 - figure supplement 1B). To exclude the unspecific/side effects of gene overexpression, we determined the spatial map of cell stiffness using fluorescence emission-Brillouin imaging (Elsayad et al., 2016) in the Arabidopsis root at larger area in a pEXPA15::EXPA15:mCherry line, revealing stronger mCherry signal when compared to pEXPA1::EXPA1:mCherry. The regions of higher Brillouin frequency shift correlated well with EXPA15 expression domain (Figure 6), suggesting the role of EXPA15 in the control of $\mathrm{CW}$ stiffness. On the other hand, we did not detect any changes in the CW stiffness in the root TZ of expa1-1 knock-out line (Pacifici et al., 2018) when compared to WT (Figure 5 - figure supplement 3).

Since the refractive index (RI) in cells directly correlates with the mass content, we applied quantitative cell tomography (employing a holotomographic microscope) to measure the RI directly in the Arabidopsis roots in water. Representative maximum intensity projections of RI tomograms are shown in Figure 7A. The quantitative data analysis confirmed that there are no statistically significant differences across all genotypes and treatment performed in both longitudinal (upper graphs) and transverse (lower graphs) cell walls of the early elongating cells in Arabidopsis roots grown at both $\mathrm{pH} 4$ and 5.8 (Figures 7B, C). 
To directly measure the "stiffness" of root CWs, we used atomic force microscopy (AFM). AFMbased microindentations apply precise known forces on a cell through a cantilever and give a deformation value to extract cell Young's modulus (Peaucelle, 2014; Peaucelle et al., 2015). In a complex structure of plant tissues, at small deformation the force to deform material is proportional to the area of indentation allowing the determination of a coefficient of proportionality that is named "apparent Young's modulus" (Peaucelle, 2014). This coefficient depends on the speed of deformation and mechanical characteristics of the sample. Representative heat maps of the apparent Young's modulus $\left(E_{A}\right)$ show clear differences in $E_{A}$ measured in the $C W$ of root early $E Z$ in 7-day old Arabidopsis WT and EXPA1 overexpressing seedlings (Fig. 8A). The data quantification confirms that the Dex-induced EXPA1 associates with significantly stiffer roots $(\mathrm{P}<0.001)$ on growth media at $\mathrm{pH} 5.8$ or $\mathrm{pH} 4$ (Figure 8B and $\mathrm{C}$, respectively). The stiffening effect of EXPA1 overexpression thus seems to be observable at indentation speed of seconds and at the $\mathrm{GHz}$ through the Brillouin technique.

To wrap up, overexpression of EXPA1 results into stiffening of the CWs measured at the TZ/EZ boundary using both Brillouin light scattering and AFM. Interestingly, even the natural EXPA15 expression seems to associate with cells revealing higher stiffness within the Arabidopsis root tip.

\section{EXPA1 overexpression downregulates root growth by reducing RAM size}

We examined the phenotype of WT and EXPA1 overexpressing seedlings (pRPS5A>GR>EXPA1 lines 5-4 and 8-4) grown on Dex continuously for 1 week. The Dex-induced plants had significantly reduced length of roots by $25-30 \%$ (Figures 9A, B). The reduction was further enhanced to $40-$ $73 \%$ when the $\mathrm{pH}$ of the growth media was dropped from 5.8 to 4 . A detailed examination of the RAM together with the TZ revealed that the size was significantly reduced by $18 \%$ and $29 \%$ for the line 8-4 grown on media with normal (5.8) and acidic (4) $\mathrm{pH}$, respectively (Figures 9C). Similarly, the number of the cells (counted in the cortex layer from the quiescent centre to the first elongated cell) was significantly reduced (Figure 9D). However, the ratio size/number of cells remained the same for each line with or without Dex induction (Figure 9E), suggesting that the number of the cells, but not the cell length is reduced in the smaller roots.

To determine the possible mechanism of root shortening in more details, we assayed the impact of EXPA1-overexpression on the longitudinal root zonation. Here, we used the cell morphology criteria as defined by Takatsuka et al. (2018). Our data show that while the number of cells in the TZ remained similar to those of WT, the number of cells in the RAM (the proximal meristem) was significantly reduced upon EXPA1 overexpression (Figure $9 \mathrm{E}, \mathrm{F}$ ).

In contrast to previous reports, in our hands expa1-1 (Pacifici et al., 2018), expa1-2 (Ramakrishna et al., 2019) as well as our Dex-inducible amiRNA (amiEX1 lines), designed to downregulate EXPA1 and closely related EXPA14 and EXPA15, did not display any significant phenotype in terms of root or RAM size (Figure 9 - figure supplement 1). However, it should be noted here that the amiEX1 lines only reduced the EXPA1 expression after Dex induction by app. 50\%, EXPA14 by $60 \%$ and EXPA 15 by $90 \%$ (tested by RT qPCR, data not shown).

Taking together, while we do not see any effect of EXPA1 absence/downregulation on the root growth and/or RAM size, the overexpression of EXPA1 results into reduction in a number of proliferating cells in the root meristem, thus slowing down the growth of the Arabidopsis root. 


\section{DISCUSSION}

\section{Is there a role for hormonal regulation over EXPA1 in the root growth?}

Recently, the role of Arabidopsis EXPA1 was described in the early stages of lateral root formation (Ramakrishna et al., 2019) and in the control of cell differentiation (expressed as a function of cell elongation) in the cells leaving meristematic zone of RAM (Pacifici et al., 2018). In the latter work, the authors proposed cytokinin-mediated upregulation of EXPA1 and two genes encoding $\mathrm{H}^{+}$ATPases in the root TZ/EZ boundary and in the RAM, respectively, as a mechanism of cytokinininduced cell differentiation. Pacifici et al. (2018) reported expansion of RAM in the expa1-1 background compared to the WT. Furthermore, the authors claimed that the phenotype could be rescued in the presence of construct for translational fusion of EXPA1 with GFP (pEXPA1::EXPA1:GFP), suggesting functionality of the construct even though no GFP signal could be detected. In line with more recent study (Ramakrishna et al., 2019), we did not observe any statistically significant change in the root length and/or RAM size in the expa1-1, CRISPR/Cas9 line expa1-2 and our amiRNA lines. Nonetheless, it should be stressed here that exp1-2 is hypomorphic allele (Ramakrishna et al., 2019) and our amiRNA lines are knock-down (not knock-out) lines. In contrast to Pacifici et al. (2018), we also did not observe the EXPA1:mCherry outside the columella/LRC in the root tip and the promoter activity (pEXPA1::nls:3xGFP) was only occasionally seen in the TZ/EZ boundary and in the elongated cells proximally to that. In accord with that, we did not detect any changes in the CW stiffness in the root TZ of expa1-1. Finally, cytokinins only moderately and transiently activated EXPA1 transcription when assayed in the entire roots using RT qPCR. However, no statistically significant upregulation was detectable (using absolute fluorescence measurement) in the RAM using the pEXPA1::nls:3xGFP and pEXPA1::EXPA1:mCherry lines after 6 h treatment with both BAP or NAA. These findings are suggesting that the cytokinin-mediated transcriptional regulation of EXPA1 may take place in other parts of the root (e.g. cells surrounding LR primordia). Similarly to us, Pacifici et al. (2018) also did not see the cytokinin-dependent regulation in the columella/LRC and claim that $A R R 1$ mediates the cytokinin control over EXPA1 expression specifically in the TZ/EZ boundary. Considering the EXPA1 expression potentially taking place in the TZ/EZ boundary would represent negligible proportion of the entire expression of EXPA1 in the root, its developmental importance is rather questionable and seems unlikely to be responsible for the observed (3-4 times) upregulation of EXPA1 transcript in the Arabidopsis root. Based on our data, we do not exclude the role of EXPA1 in the control of RAM size, but probably in a concert with other EXPAs and dominantly in the columella/LRC (vide infra). The role of (cytokinin-regulated) auxin accumulation in the LRC in the control of RAM size has been proposed recently (Di Mambro et al., 2019). However, even in case of more distinct transcriptional regulation of EXPA1 by NAA, we do not see any significant and consistent EXPA1 upregulation in the LRC, both at the level of promoter activity or EXPA1 protein (data not shown), thus leaving the functional importance of cytokinin- and auxin-mediated regulation over EXPA1 in the root tip rather unclear.

\section{EXPA localization and control of CW properties}

In the previous studies, expansins were located to the CWs using immunolocalization techniques of fixed plant materials (Zhang and Hasenstein, 2000; Cosgrove et al., 2002; Balestrini et al., 2005). The transgenic lines carrying EXPA genes in a translational fusion with mCherry allowed 
observing localization of EXPA proteins, to our knowledge for the first time, in living plants. Interestingly, our data suggest that assayed EXPAs differ not only in the spatiotemporal specificity of expression, but their protein products reveal also distinct localization pattern in specific domains of the root apoplast. Firstly, we see localization of EXPA10 and EXPA14 dominantly in the longitudinal CWs of elongated root cells. This is resembling the situation observed in maize xylem, where the signal obtained after immunolocalization using anti-cucumber expansin antibody was homogenously distributed in the isodiametric (non-elongated) xylem cells, while located dominantly to the longitudinal CWs of elongated xylem (Zhang and Hasenstein, 2000). Secondly, EXPA10, EXPA14 and (partially) EXPA15 located in a punctuate pattern, spatially colocalizing with the three-cell boundaries, possibly surrounding the intercellular space. Plant as well as bacterial expansins were found to bind cellulose rather weakly (McQueen-Mason and Cosgrove, 1995), in case of bacterial EXLX1 via hydrophobic interactions (Georgelis et al., 2011). Much stronger affinity was observed between expansins and components of the CW matrix, including pectin and hemicelluloses (McQueen-Mason and Cosgrove, 1995; Georgelis et al., 2011). These and other evidence, e.g. the ability of expansins to mechanically weaken pure paper (McQueenMason and Cosgrove, 1994) led to a conclusion that expansins bind at the interface between cellulose microfibrils and polysaccharides in the $\mathrm{CW}$ matrix inducing the $\mathrm{CW}$ extension by reversibly disrupting the noncovalent bonds within this polymeric network (McQueen-Mason and Cosgrove, 1995). In the same study, the authors propose that an unknown minor structural component of the $\mathrm{CW}$ matrix might be responsible for expansin binding and action. In a more recent work using solid-state nuclear magnetic resonance (NMR) in a combination with differential isotopic labelling of expansin and polysaccharides, Wang et al. (2013) discovered that expansin binds highly specific cellulose domains enriched in xyloglucan, while the previously reported and more abundant binding to pectins doesn't seem to relate to its activity. Our results imply existence of a factor determining specific localization of individual EXPAs in different $\mathrm{CW}$ compartments, particularly those revealing the specific "spotty" localization. The homogenous distribution of EXPA1 throughout the CWs even outside its natural expression domain as seen in the pRPS5A>GR>EXPA1:mCherry line is suggesting that the specific localization pattern is not celltype specific, but rather encoded in the EXPAs amino acid sequence. The absence of colocalization of EXPA10 with calcofluor white staining in the fixed Arabidopsis root is implying that the factor could be a component of the CW matrix other than cellulose. The existence of the putative factor responsible for targeting subset of EXPAs into specific apoplast domains and its (molecular and/or biophysical) nature, however, remains elusive.

Arabidopsis genome contains 26 genes for a-expansins (Li et al., 2002), suggesting functional diversification within the subfamily. Specific expression and localization of EXPA1, EXPA10, EXPA 14 and EXPA15 together with differential hormonal sensitivity implies possible functional crosstalk among the individual expansins. Concert in their targeted action in the apoplastic continuum encapsulating the individual cells might result into the final vectorial change of CW expansion and highly coordinated cellular behaviour underlying root growth including its longitudinal zonation. Similar functional and spatiotemporal specificity including differential hormonal response and shoot cell growth-based zonation was described for LeEXP2, LeEXP9 and LeEXP18 in tomato (Caderas et al., 2000; Vogler et al., 2003). Using two independent approaches, the non-invasive Brillouin light scattering imaging and AFM we have shown that overexpression of EXPA1, homogenously distributed throughout the $\mathrm{CW}$, results into increased 
CW stiffness in the root cells. That suggests that deregulating the tightly controlled equilibrium of specific expression and localization of individual EXPAs probably disturbs the naturally occurring strain/stress distribution within the growing Arabidopsis root that is reflected in the increased stiffness of the root cells and consequently root growth arrest. This might be analogous to the situation observed after misregulation of bipolar distribution of pectin methylesterase activity in the Arabidopsis hypocotyls. Peaucelle et al. (2015) demonstrated asymmetric loosening of longitudinal, as compared to transverse (anticlinal) walls just before the cell starts to elongate, even preceding the cortical microtubule reorientation, considered as a reporter of CW tensions (Hamant et al., 2019). It is achieved via asymmetric pectin de-methylesterification, as reliably shown via immunolabeling of low degree of homogalacturonan methylesterification in epidermal hypocotyl CWs using 2F4 antibody. As anticipated, manipulation of homogalacturonan demethylesterification through the inducible overexpression of the pectin methylesterase (PME5oe) or the PME inhibitor 3 (PMEI3oe) significantly increased or reduced 2F4 signal, respectively. That associated with reduction/increase of the overall cell stiffness in PME5oe/PMEI3oe plants. However, in both cases, the loss of asymmetry in the CW matrix composition and its biomechanical properties led to the similar effect, i.e. loss of cell expansion. Similar mechanism i.e. disturbing the tightly regulated spatial distribution of individual expansins might be the reason of contrasting effects of expansins overexpression, frequently associated with upregulated $\mathrm{CW}$ expansion, but sometimes leading to the opposite effect. i.e. cell growth inhibition (Caderas et al., 2000; Cho and Cosgrove, 2000, 2002; Choi et al., 2003; Vogler et al., 2003; Zenoni et al., 2011; Goh et al., 2014).

According to the loosening theory in a well-hydrated non-growing cell, the cell reaches osmotic equilibrium, with wall stresses counter-balancing the outward force of turgor pressure against the wall. However, growing CWs are loosened which refers to a shift or cut of a load-bearing part of the wall, relaxing tensile stress in the entire wall and simultaneously reducing cell turgor. As a result, water flows into the cell, elastically expanding the wall and restoring turgor and wall stress (Cosgrove, 2018b). CWs may become mechanically softer (meaning more easily deformed by mechanical force), but they do not necessarily result in an increase in wall relaxation and growth, e,g, lytic enzymes may soften CW but do not stimulate cell growth. On the other hand, $\alpha$-expansins cause stress relaxation and prolonged enlargement of CWs, but they lack wall lytic activity and they do not soften the wall, as measured by tensile tests (Cosgrove 2018b, Wang and Cosgrove, 2020). An example of such observations was made by Wang and Cosgrove (2020) with pectin methylesterase (PME) that selectively softened the onion epidermal wall yet reduced expansinmediated creep. After enzymatic de-esterification (without added calcium), the onion epidermal wall swelled and became softer, as assessed by nanoindentation (AFM) and tensile plasticity tests, yet exhibited reduced acid-induced creep. Accordingly, $\alpha$-expansins were shown to act via different mechanism as compared to enzymes inducing $\mathrm{CW}$ creep via modifying $\mathrm{CW}$ matrix. Compared to $\mathrm{CW}$ loosening mediated by fungal endoglucanase Cel12A, expansins do induce $\mathrm{CW}$ loosening that is not associated with changes in the tensile stiffness (neither elastic nor plastic compliance), suggesting different way of action (Yuan et al., 2001). Another example is deesterification of homogalacturonan (HG) that is thought to stiffen pectin gels and primary CWs by increasing calcium crosslinking between HG chains. Contrary to this idea, recent studies (Braybrook and Peaucelle, 2013; Peaucelle et al., 2015) found that HG de-esterification correlated with reduced stiffness of living tissues, measured by surface indentation. The physical basis of 
such apparent wall softening is unclear, but possibly involves complex biological responses to HG modification. Indeed, feedback mechanisms and other factors regulating $\mathrm{CW}$ remodelling genes evoked by CW integrity pathway sensors often complicate the interpretation of $\mathrm{CW}$ mutant lines (Gigli-Bisceglia et al., 2018).

In terms of the methodological approach used, there are important differences between the longitudinal elastic modulus (M) measured by Brillouin light scattering and the Young's modulus (E) measured via AFM (Prevedel et al., 2019). The BLS measured M is well known to be very sensitive to the level of hydration (Palombo et al., 2014; Wu et al., 2018; Androtis et al., 2019) and temperature (Berne and Pecora, 2000), and any comparisons have thus to be made under the same thermodynamic conditions and hydration levels. However, as these can be assumed to be similar between the different samples measured, variations between samples can be interpreted as being due to changes in the mechanical properties in the probed regime. The comparable trend of the AFM measured quasi-static Young's Modulus and BLS measured MOC observed here, is consistent with observations in other diverse biological samples (e.g. Andriotis et al., 2019; Gouveia et al., 2029; Scarcelli et al., 2015) suggesting that here too the latter may serve as a proxy for stiffness. We note, however, that at very high hydration levels (much higher than in the system studied here), any relation between the two can be expected to break down (Wu et al., 2018).

One possible interpretation of the unexpected increase of $\mathrm{CW}$ stiffness upon EXPA1 overexpression is the aforementioned disturbance of the coordinated equilibrium in the $\mathrm{CW}$ tensions across the Arabidopsis root and tissue-wide mechanical conflicts, shown to be an important morphogenic mechanism involved in the petal development in snapdragon (Rebocho et al., 2017). That might result to the general block in the CW extensibility, possibly potentiated via proposed mechanosensitive feedback loop (Uyttewaal et al., 2012), leading to absence of CW relaxation and thus increased stiffness. However, our large area mapping of $\mathrm{CW}$ stiffness using fluorescence emission-Brillouin imaging at small magnification implies colocalization of natural EXPA15 expression with regions of higher stiffness. This is implying a possible role for cell stiffening even in case of endogenous expansins. Nonetheless, the molecular/biophysical mechanism underlying this contra intuitive effect remains to be clarified.

\section{Conclusions}

Based on our and others' results (vide supra), we suggest that the tightly controlled spatiotemporal specificity of expansin expression in a combination with localisation of their protein products into distinct domains of plant extracellular matrix, together with hormone-regulated $\mathrm{pH}$ distribution within the root apoplast (Barbez et al., 2017), plays an important regulatory role controlling the root growth and development in Arabidopsis. Similar concept suggesting the role of regular (i.e. controlled) distribution of mechanically stiff regions in the extracellular matrix for the proper transcriptional regulation and actin-dependent cellular adhesion associated with stem cell fate determination was published in animal system (Yang et al., 2016).

The expansin-mediated regulation of the biomechanical CW properties seems to be associated with subsequent mechanoperception-mediated feedback loop, leading to genome-wide changes in the expression profiles of individual cells, probably in a cell type-specific context (llias et al., 2019). However, our results on the short-term induction of EXPA1 expression associated with 
prompt increase in the CW stiffness imply that the non-transcriptional regulation will be an important mechanism underlying EXPA(1)-controlled CW biomechanics and root growth.

Upregulated EXPA1 associated with CW stiffness seems to downregulate root growth via downregulating RAM size. This is suggesting a mechanism connecting biomechanical $\mathrm{CW}$ properties with the control over cell division in the RAM. Whether the mechanism includes the CW integrity signalling, previously shown to control cell division in the RAM in a response to the inhibition of cellulose biosynthesis (Gigli-Bisceglia et al., 2018), remains to be identified.

\section{ACKNOWLEDGEMENT}

M.S. has received funding from the European Union's Horizon 2020 research and innovation programme under the Marie Skłodowska-Curie co-financed by the South Moravian Region under grant agreement No. 665860. This study reflects only the author's view and the EU is not responsible for any use that may be made of the information it contains. The work was further supported by the Ministry of Education, Youth and Sports of CR from European Regional Development Fund-Project "Centre for Experimental Plant Biology": No. CZ.02.1.01/0.0/0.0/16_019/0000738, LTAUSA18161 and LTC19047 and Czech Science Foundation (19-24753S). K.E. acknowledges support from the City of Vienna and the Austrian Ministry of Science (Vision 2020). The work of E.V.Z. and E.V.U. was supported by the Russian Science Foundation (20-14-00140) and the Russian State Budget (0324-2019-0040). We acknowledge Plant Sciences and Cellular Imaging CFs at CEITEC MU supported by MEYS CR (LM2018129). RIAT-CZ project (ATCZ40) funded via Interreg V-A Austria - Czech Republic is gratefully acknowledged for the financial support of the measurements at the Vienna Biocenter CF Advanced Microscopy. We thank to Ive De Smet for his kind donation of the pEXP1::nls:3xGFP, Alexis Maizel for CRISPR/Cas9 exp1-2 Arabidopsis lines and Victoria Mironova for critical reading of the manuscript. 
bioRxiv preprint doi: https://doi org/10.1101/2020.06.25.170969; this version posted July 31, 2020. The copyright holder for this preprint (which was not certified by peer review) is the author/funder, who has granted bioRxiv a license to display the preprint in perpetuity. It is made available under aCC-BY-NC-ND 4.0 International license.

\section{FIGURES AND FIGURE LEGENDS}

A

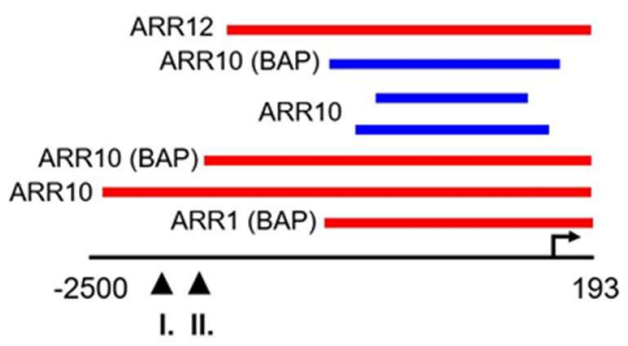

B

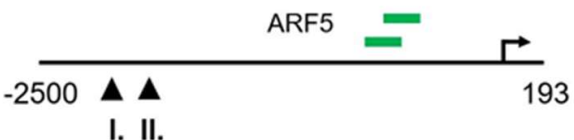

C

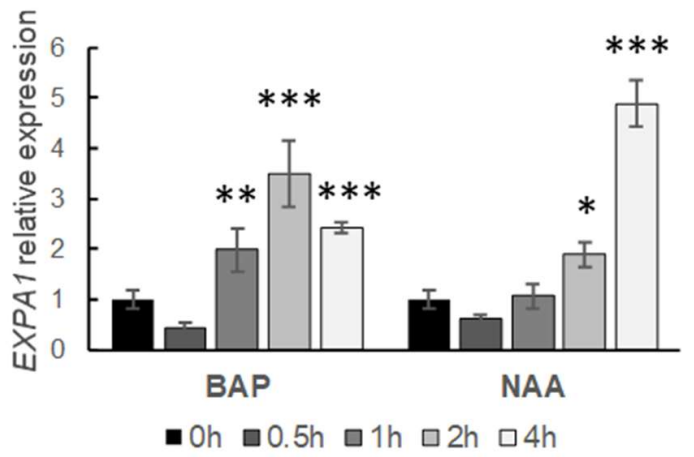

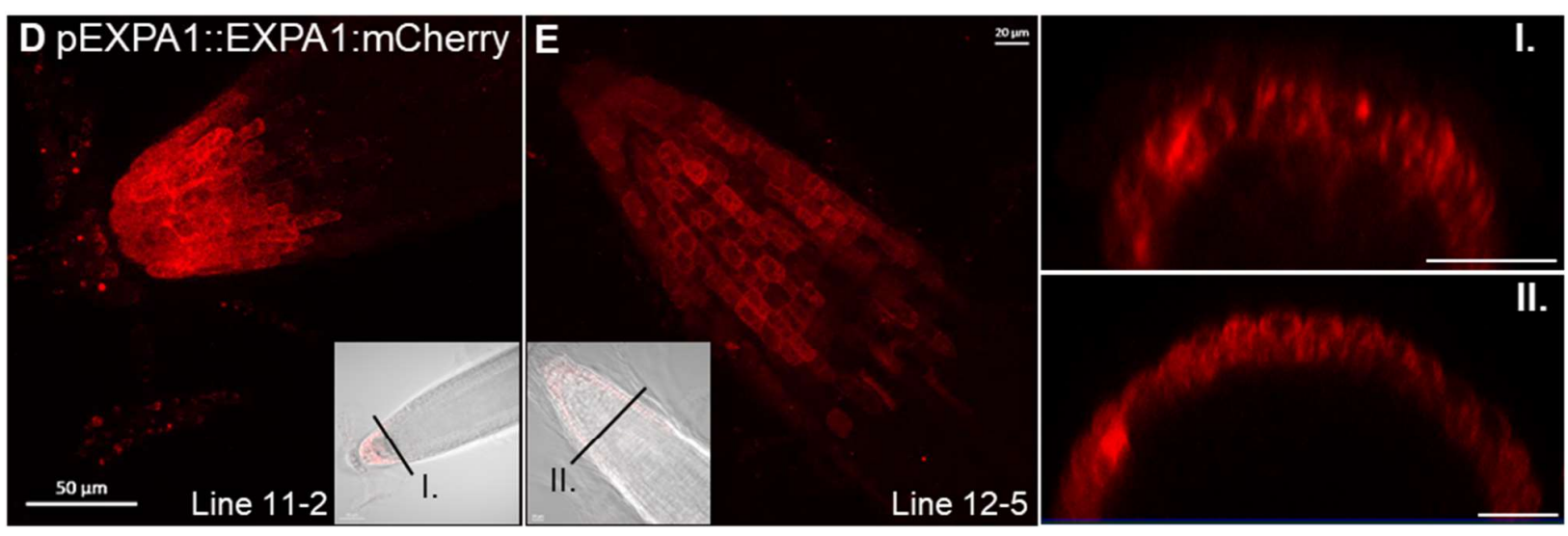

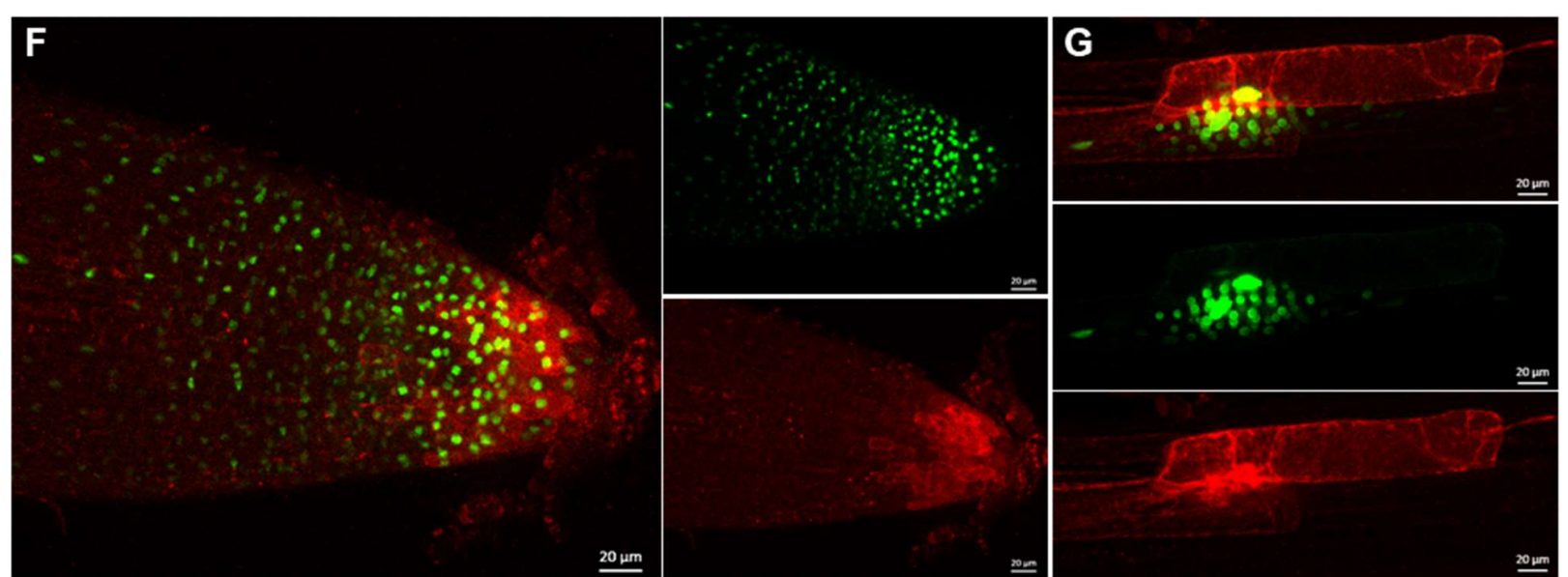

Figure 1: Transcript profiling of EXPA1 in response to hormones, EXPA1 promoter activity and EXPA1 localization.

(A) EXPA1 promoter analysis identifies ChIP-seq- and DAP-seq-derived binding events for transcription factors involved in cytokinin and (B) auxin signalling pathways. Red, blue and green colours depict the peaks from Xie et al., 2018, Zubo et al., 2017 and O'Malley et al., 2016, respectively. The coordinates are represented relative to the transcription start site marked by the 
arrow. The arrowheads indicate the 5'-end of the pEXPA1 promoter in (I.) this publication and (II). Pacifici et al., 2018. (C) Quantitative real-time PCR of roots of 7-day old Arabidopsis WT seedlings treated with $5 \mu \mathrm{M}$ BAP or $5 \mu \mathrm{M}$ NAA for $0.5 \mathrm{~h}, 1 \mathrm{~h}, 2 \mathrm{~h}$ and $4 \mathrm{~h}$. The transcript abundance of EXPA1 is double normalized to UBQ10 and mock-treated controls. The experiment was repeated twice with 3 replicas of each sample, error bars represent SD. Statistically significant differences at alpha $0.05\left(^{*}\right), 0.01\left(^{* *}\right)$ and $0.001\left(^{(* *}\right)$ are shown. (D, E) Z-stack projections of pEXPA1::EXPA1:mCherry fusion localised in the LRC and columella of two independent singlecopy transgenic lines 11-2 (D) and 12-5 (E) and their transversal $x z$ optical sections (I. and II.) as indicated by the black lines in the transmitted-light micrograph inserts shown as a single optical section. (F, G) Z-stack projections of $F 1$ line pEXPA1::EXPA1:mCherry (11-2) crossed with pEXPA1::nls:3xGFP illustrating a similar pattern of EXPA1 expression by GFP (green) and mCherry (red) signals in RAM $(F)$ and lateral root primordium $(G)$. Scale bars correspond to 20 $\mu \mathrm{m}$ except in $\mathrm{D}$, where it corresponds to $50 \mu \mathrm{m}$.

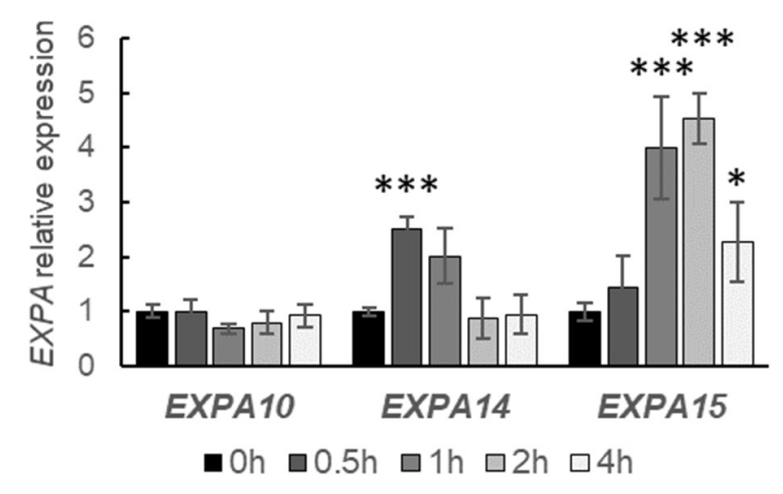

Figure 2: Transcript profiling of EXPA10, EXPA14 and EXPA15 in a response to cytokinin treatment.

Quantitative real-time PCR of roots of 7-day old Arabidopsis WT seedlings treated with $5 \mu \mathrm{M}$ BAP for $0.5 \mathrm{~h}, 1 \mathrm{~h}, 2 \mathrm{~h}$ and $4 \mathrm{~h}$. The transcript abundance of the EXPAs is double normalized to UBQ10 and mock-treated controls. The experiment was repeated twice with 3 replicas of each sample, error bars represent SD. Statistically significant differences at alpha $0.05\left(^{*}\right)$ and $0.001\left(^{* *}\right)$ are shown. 
bioRxiv preprint doi: https://doi.org/10.1101/2020.06.25.170969; this version posted July 31, 2020. The copyright holder for this preprint (which was not certified by peer review) is the author/funder, who has granted bioRxiv a license to display the preprint in perpetuity. It is made available under aCC-BY-NC-ND 4.0 International license.
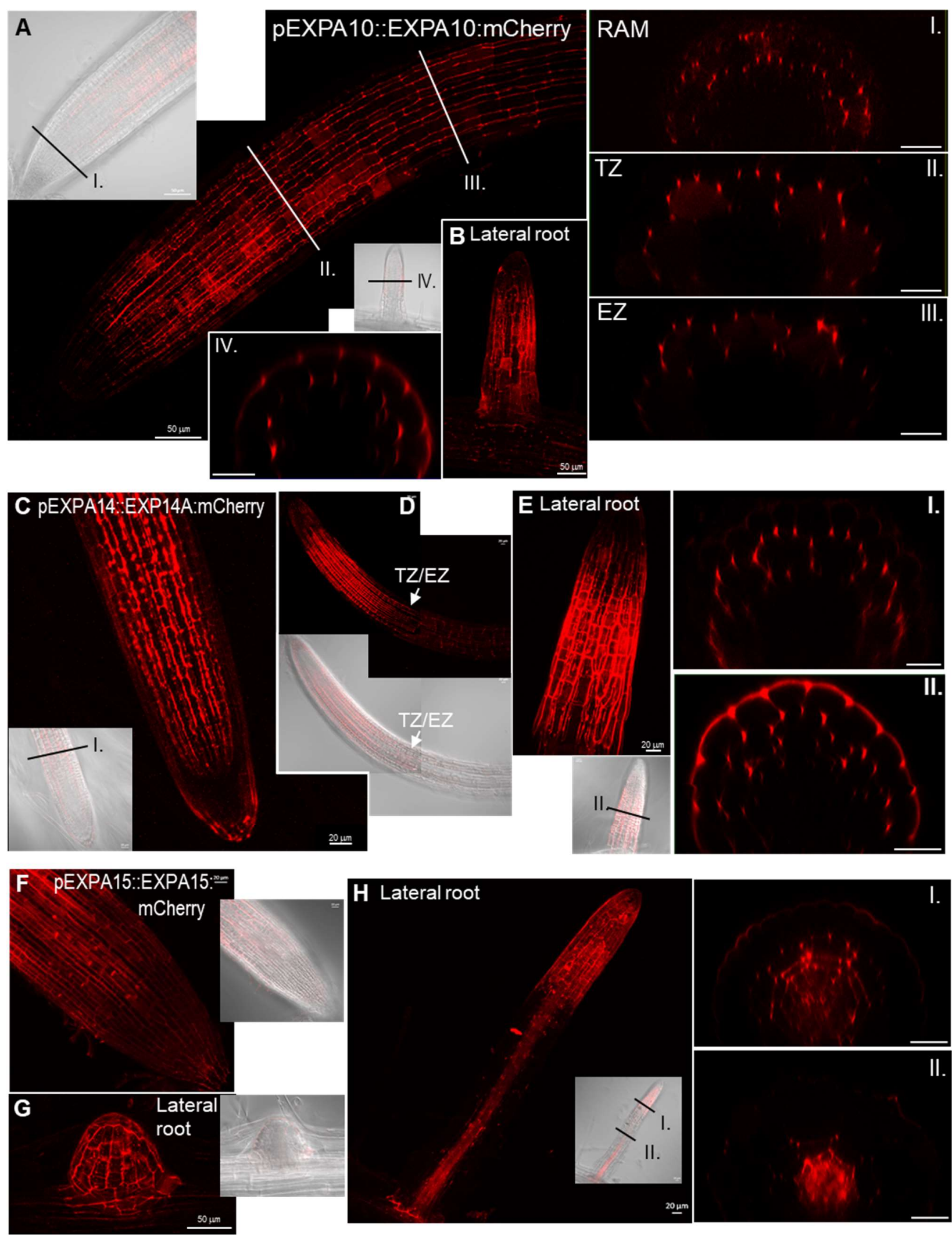

Figure 3: EXPA10, EXPA14 and EXPA15 reveal specific localization in the root tip. 


\begin{abstract}
(A, B) pEXPA10::EXPA10:mCherry in a primary $(A)$ and lateral $(B)$ root and transversal $x z$ optical sections (I.-IV.) through the RAM, transition (TZ) and elongation (EZ) zones and the lateral root as indicated by the black and white lines in the longitudinal plane views. (C-E) pEXPA14::EXPA14:mCherry in a primary $(C, D)$ and lateral $(E)$ root and transversal $x z$ optical sections (I. and II.) as indicated by the black lines in the longitudinal plane views; the white arrows point to the TZ/EZ boundary. (F) pEXPA15::EXPA15:mCherry in RAM, (G) an emerging lateral root, $(\mathbf{H})$ a lateral root and its transversal $x z$ optical sections (I. and II.) as indicated by the black lines. Z-stack projections from optical sections taken from the top of the root to the longitudinal plane are shown in all longitudinal plane views. Transmitted-light micrograph inserts show a single optical section. Scale bars correspond to $20 \mu \mathrm{m}$ except in A, B, G, where they correspond to 50 $\mu \mathrm{m}$.
\end{abstract}




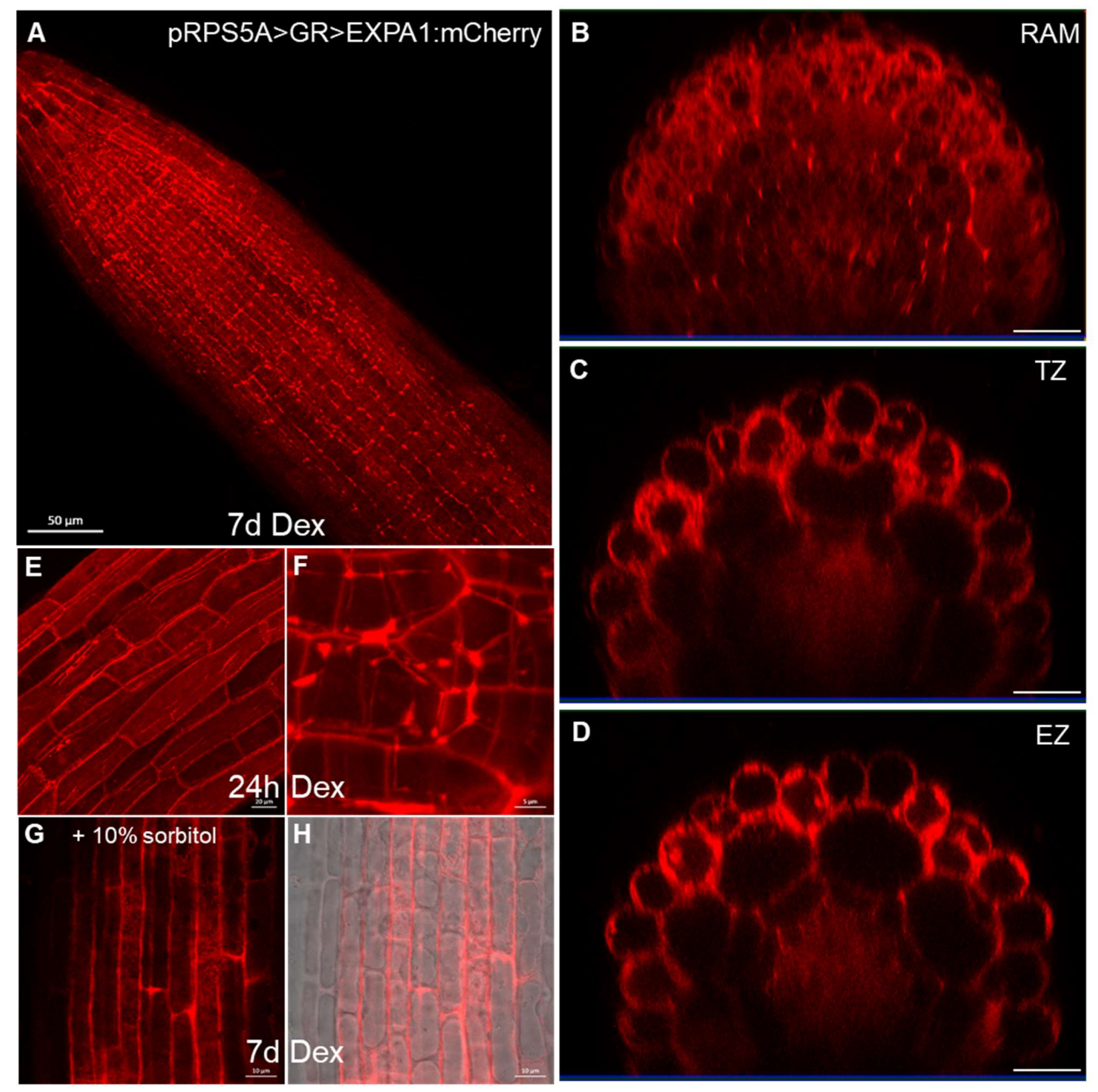

Figure 4: Overexpressed EXPA1 localizes to the cell wall.

Z-stack projections of EXPA1:mCherry fluorescence in pRPS5A>GR>EXPA1:mCherry seedlings induced by Dex on a solid MS medium for $7 d$ in a primary root (A) and its $x z$ optical cross-sections through RAM (B), TZ (C) and EZ (D). (E, F) pRPS5A>GR>EXPA1:mCherry seedlings induced by Dex in a liquid $M S$ medium for $24 \mathrm{~h}$ and imaged $E Z$ of a primary root $(E)$ and a lateral root $(F)$. $(G, H)$ pRPS5A $>$ GR $>$ EXPA1:mCherry seedlings induced as in $(A)$ and after 10 min-treatment of the primary root with $10 \%$ sorbitol. Fluorescence channel $(G)$ and its overlay with transmitted light $(\mathrm{H})$. Scale bars correspond to $20 \mu \mathrm{m}$ except in $\mathrm{A}$ is $50 \mu \mathrm{m}$, in $\mathrm{F}$ is $5 \mu \mathrm{m}$ and in $\mathrm{G}$ and $\mathrm{H}$ are $10 \mu \mathrm{m}$. 


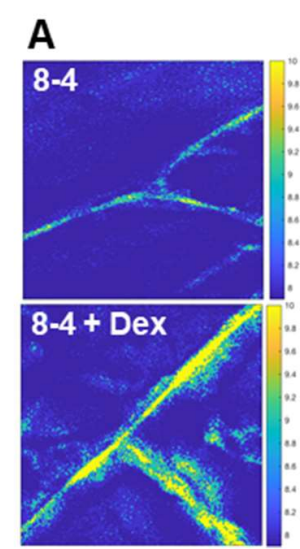

D

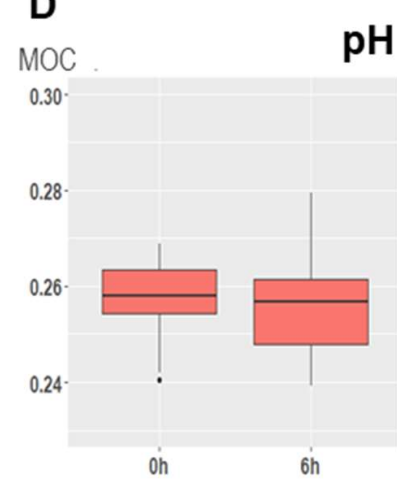

B

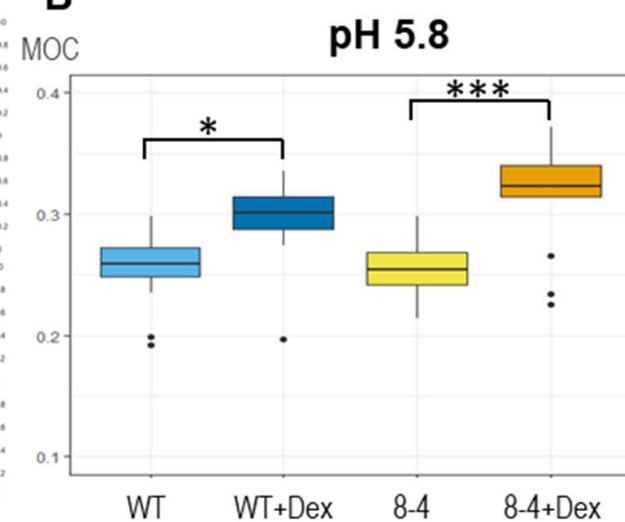

C

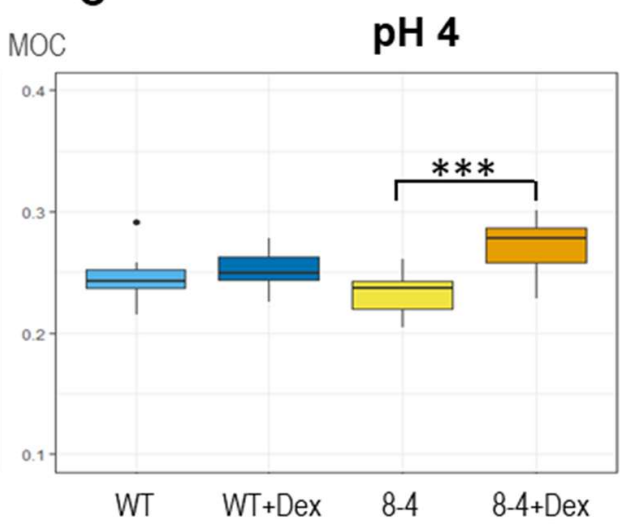

E

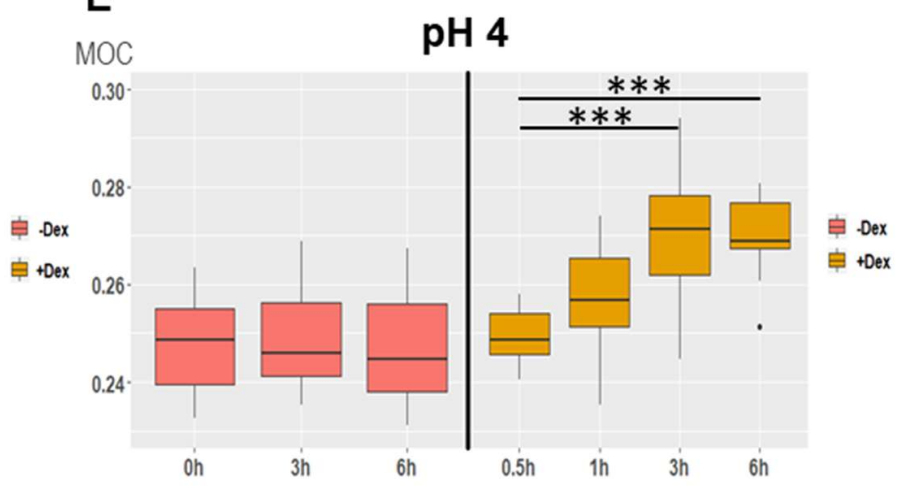

Figure 5: EXPA1 overexpression stiffens cell walls when measured via Brillouin frequency shift.

(A) Representative images of 2D (xy) Brillouin frequency shift (BFS) maps in root cells of 7-day old Arabidopsis EXPA1 overexpressing seedlings of pRPS5A>GR>EXPA1 (line 8-4) grown on MS media pH $5.8+$ +- Dex. BFS expressed as Mechano-Optical Contrast (MOC) was determined in roots of WT and the 8-4 line grown on MS media (B) +/- Dex pH 5.8, (C) +/- Dex pH 4, (D) induced in liquid MS media pH 5.8 for $0.5 \mathrm{~h}-6 \mathrm{~h}$, (E) induced in liquid MS media $\mathrm{pH} 4$ for $0.5 \mathrm{~h}-$ $6 \mathrm{~h}$; DMSO was used in -Dex treatments. Medians shown are from at least 4 seedlings and 10 measurements in each category. Statistically significant differences at alpha $0.05\left(^{*}\right)$ and 0.001 $\left(^{* * *}\right)$ are shown. 

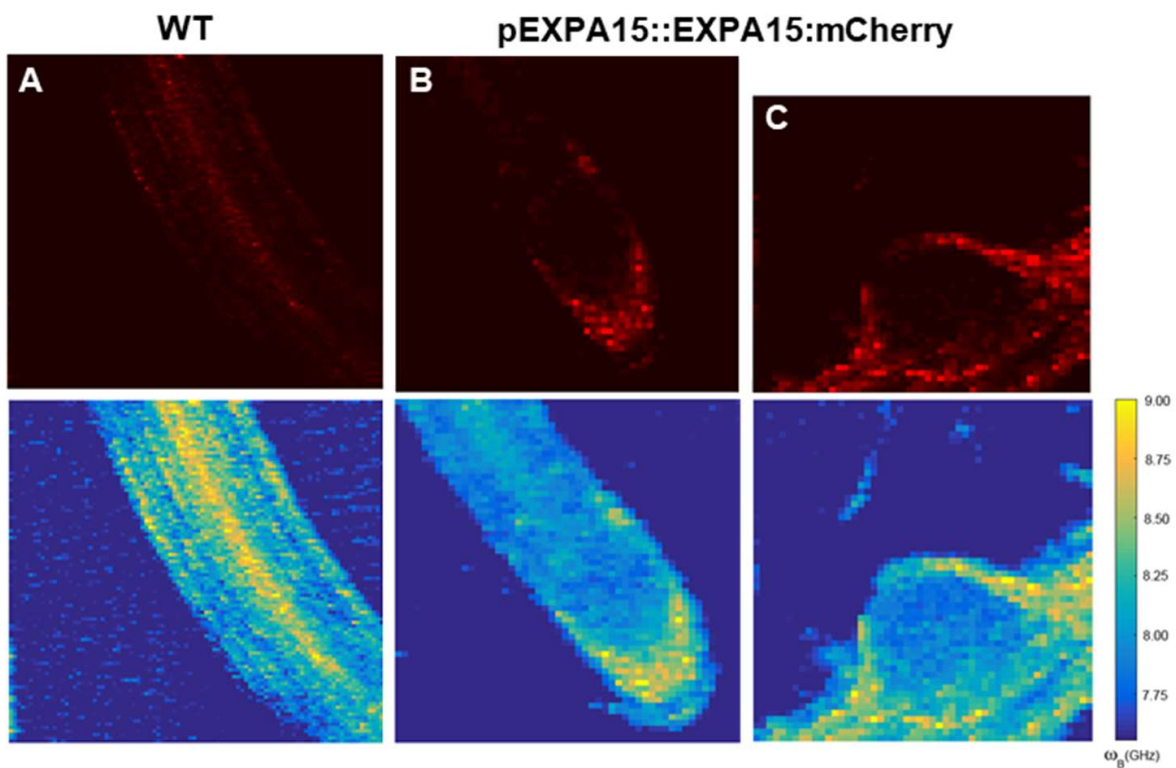

Figure 6: EXPA15 localization overlaps with higher cell wall stiffness in the root tip as determined using fluorescence emission-Brillouin scattering.

Fluorescence images (top raw, in red) and Brillouin frequency shifts (BFS, bottom raw, false colorcoded) of 7-day old Arabidopsis root of (A) WT and pEXPA15::EXPA15:mCherry (B) a primary root and $(C)$ an emerging lateral root. The fluorescent signal corresponds to EXPA15 expression and overlaps with higher BFS. 


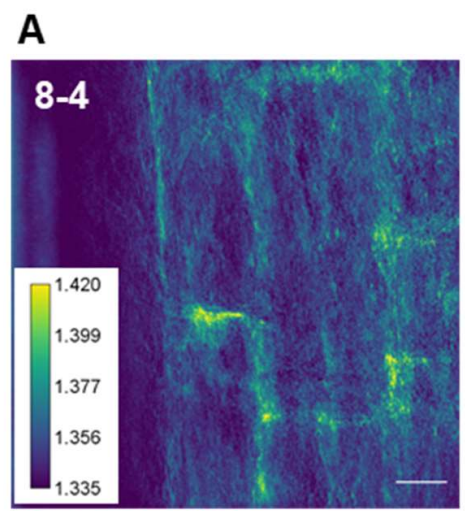

B

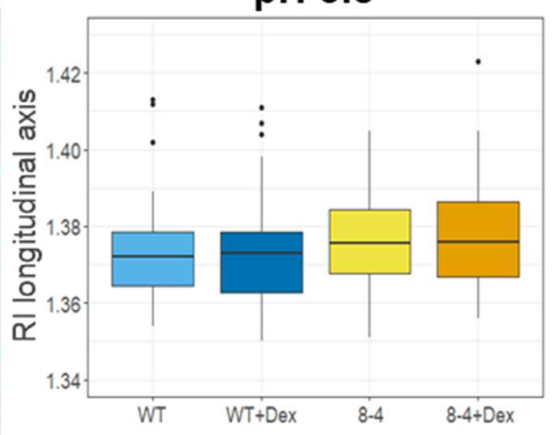

pH 5.8
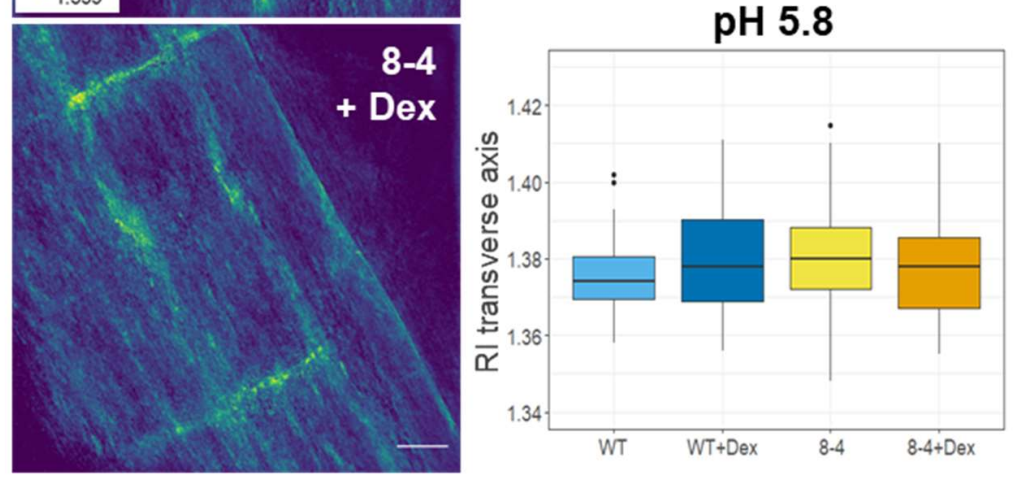

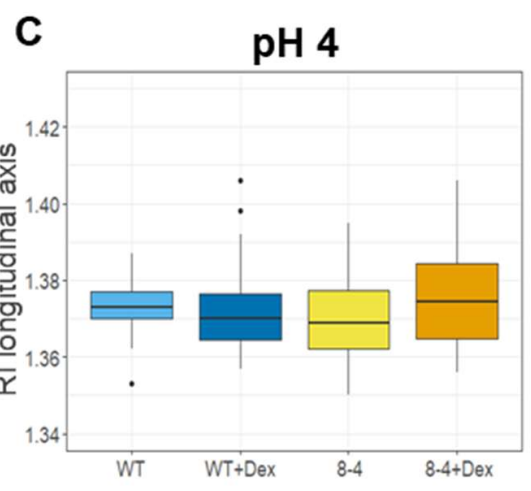

pH 4

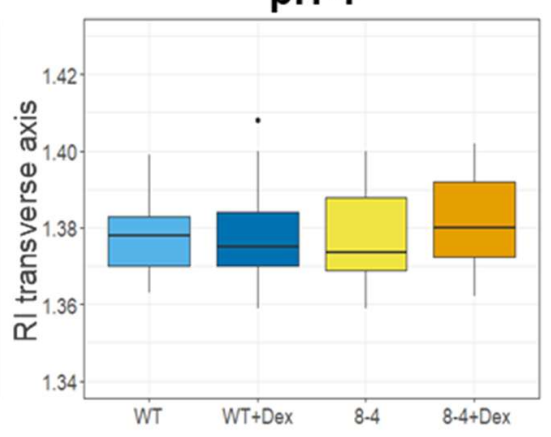

Figure 7: Refractive index measurements of Arabidopsis root cell walls reveals comparable cell wall density in wild type and EXPA1 overexpressing roots.

(A) Refractive index tomograms (maximal projections) of root cells of 7-day old Arabidopsis of EXPA1 overexpressing seedlings pRPS5A>GR>EXPA1 (line 8-4) grown on MS media pH 5.8 +/Dex. Scale bars indicate $20 \mu \mathrm{m}$. The graphs show RI measurements in water (RI 1.330) of roots of WT and the 8-4 line grown on MS media (B) +/- Dex pH 5.8, (C) +/- Dex pH 4. Medians from minimum of 6 seedlings and 30 measurements in each category of longitudinal (upper) and transverse (lower) CW axis are shown. There are no statistically significant differences between the genotypes and treatments used. 


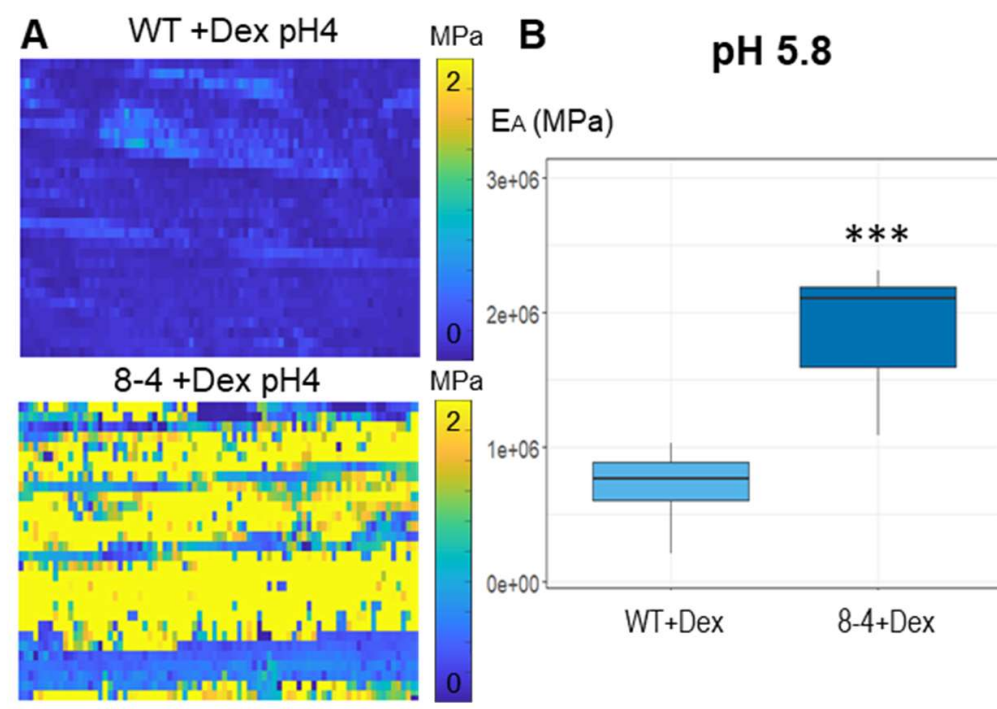

C

pH 4

$\mathrm{EA}_{\mathrm{A}}(\mathrm{MPa})$

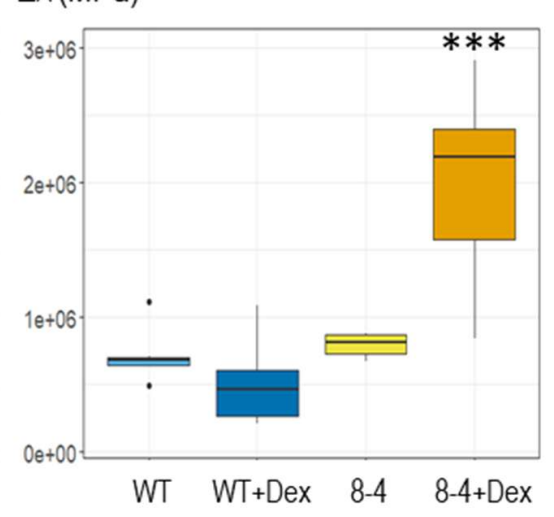

Figure 8: EXPA1 overexpression stiffens cell walls when determined using atomic force microscopy.

(A) Representative maps of the apparent Young's modulus $\left(E_{A}\right)$ of root cells of 7-day old Arabidopsis WT and EXPA1 overexpressing seedlings (line 8-4) grown on MS media $\mathrm{pH} 4$ plus Dex, showing differences in $E_{A}$ (representative of $>50$ ). The $E_{A}$ maps are presented as heat maps, with their respective scales, and show data from two successive maps of $60 \times 80$ and $60 \times 80$ force scans. Each pixel in the $E_{A}$ map represents the $E_{A}$ calculated from a single force-indentation curve, and each map consists of 4,800 data points. Images are $100 \mu \mathrm{m}$ in length. Graphs are presenting the $E_{A}$ of the roots as in (A) grown on MS media +/- Dex (B) pH 5.8 and (C) pH 4. The $E_{A}$ plotted on the graphs was determined by sampling data points within the area of interest. Medians shown are from minimum of 6 measurements in each category. Statistically significant differences at alpha $0.001\left(^{* * *}\right)$ are shown. 
bioRxiv preprint doi: https://doi.org/10.1101/2020.06.25.170969; this version posted July 31, 2020. The copyright holder for this preprint made available under aCC-BY-NC-ND 4.0 International license.
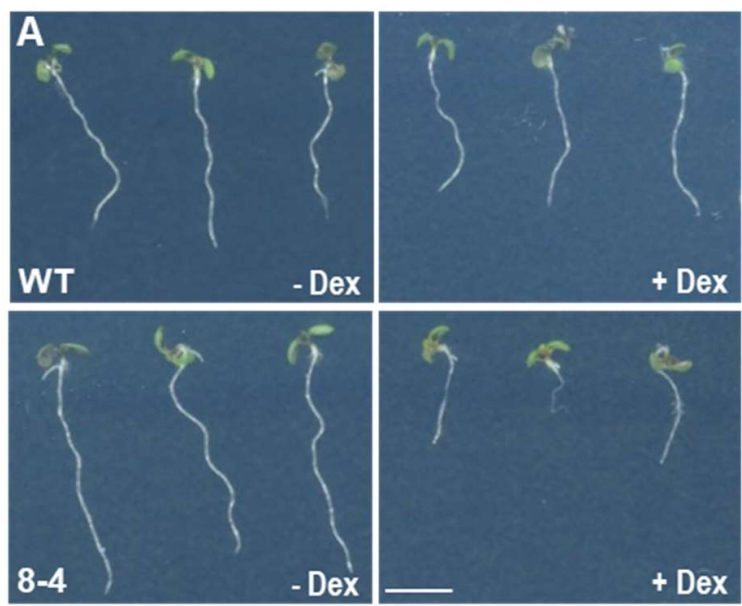

C Size of RAM + TZ

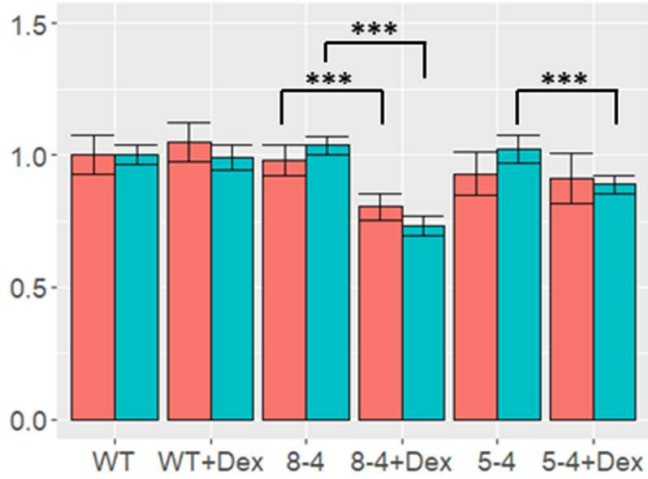

E Ratio size/ No. cells (RAM $+T Z)$

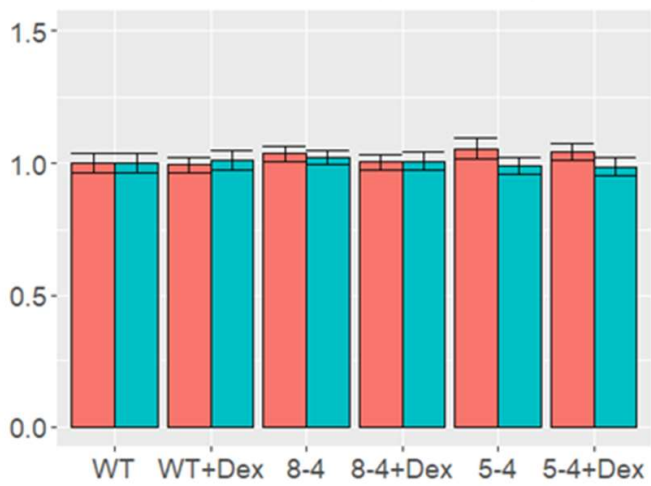

G No. cells in TZ

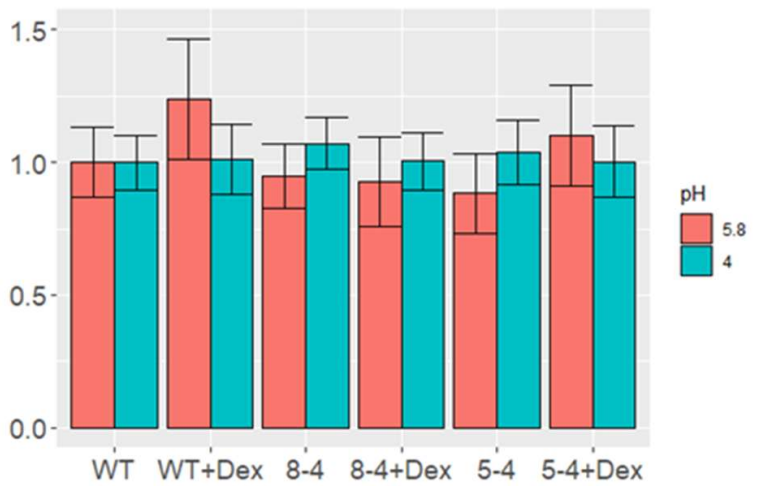

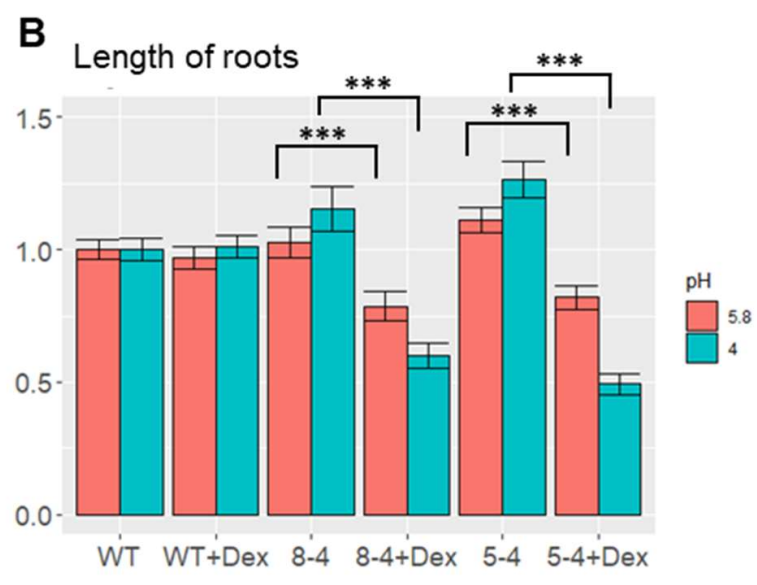

D No. cells in RAM + TZ

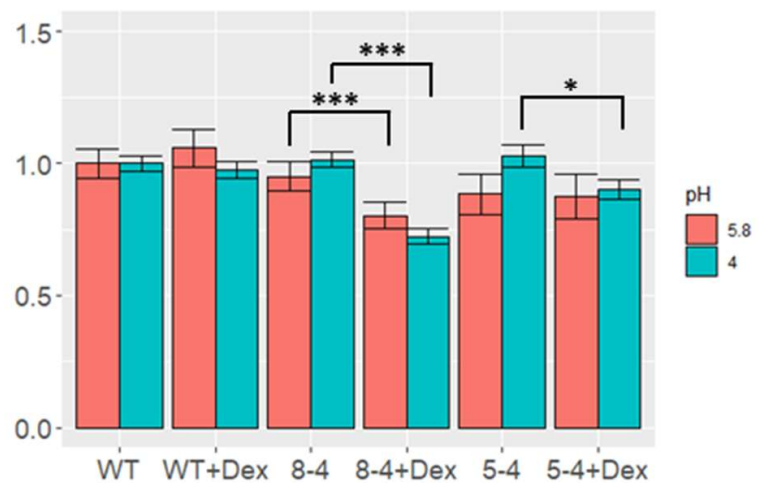

$F$ No. cells in RAM

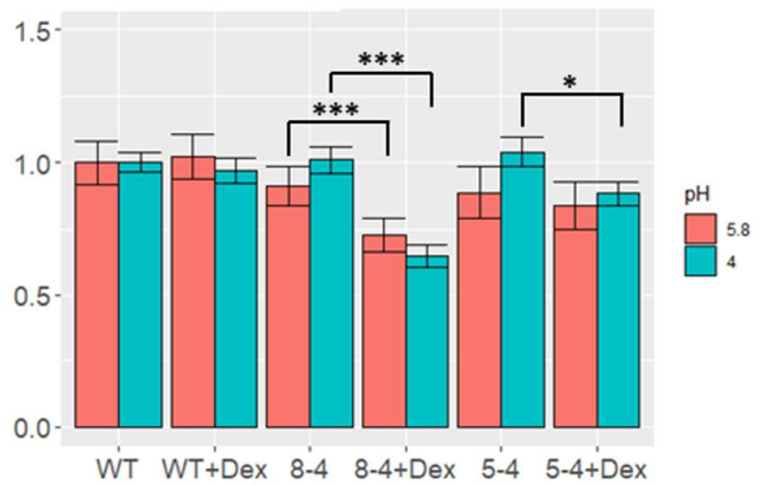


Figure 9: EXPA1 overexpression reduces root growth via shortening of the root apical meristem.

(A) 7-day old Arabidopsis seedlings of WT (top row) and pRPS5A>GR>EXPA1 line 8-4 (bottom row) grown on MS media pH4 supplemented either with DMSO (-Dex) or dexamethasone (+Dex) The scale bar is $5 \mathrm{~mm}$. (B) Length of roots, (C) size of RAM + TZ, (D) the total number of cells (No. cells) in RAM + TZ, (E) the ratio of size/ No. of cells (F) No. cells in RAM, (G) No. cells in TZ of two independent EXPA1 overexpressing lines 8-4 and 5-4 grown on MS media +/- Dex pH 5.8 and $\mathrm{pH} 4$ relative to WT. Each experiment was repeated at least three times with minimum of 10 seedlings in each category, error bars represent $95 \%$ confidence interval. Statistically significant differences within genotypes and treatments at alpha $0.05\left(^{*}\right)$ and $0.001\left(^{* * *}\right)$ are shown.

\section{MATERIAL AND METHODS}

\section{Promoter analysis}

2500 bp regions upstream of the transcription start site and entire 5'UTRs were used for prediction of TF binding regions in gene promoters. The TAIR10 version of the $A$. thaliana genome (https://www.arabidopsis.org/download_files/Genes/TAIR10_genome_release/TAIR10_ chromosome_files/TAIR10_chr_all.fas) was used for the analyses. A. thaliana genome annotation data were retrieved from Araport11 (https://www.arabidopsis.org/download_ files/Genes/Araport11_genome_release/Araport11_GFF3_genes_transposons.201606.gff.gz). To identify potential B-ARR binding regions, two sets of publicly available ChIP-seq data we used. First on ARR1,10,12 binding in 3-day old seedlings of Ypet-tagged B-ARRs lines treated with 10 UM BAP or mock treated for $4 \mathrm{~h}$ (Xie et al., 2018). Second on ARR10 binding in two to 3-week old seedlings of 35S::ARR10:GFP lines treated with 5 uM BAP or mock treated for 30 minutes (Zubo et al., 2017). To identify potential ARF binding regions we used DAP-seq data for ARF2 and ARF5 (O'Malley et al., 2016). The corresponding processed data were retrieved from Gene Expression Omnibus database (https://www.ncbi.nlm.nih.gov/geo/), the Quickload server for the Integrated Genome Browser (IGB) (bioviz.org, Freese et al., 2016) and Plant Cistrome Database (http://neomorph.salk.edu/PlantCistromeDB), respectively.

\section{Quantitative real-time transcript profiling (RT qPCR)}

Total RNA was extracted from 7-day old wild-type Arabidopsis thaliana (ecotype Columbia-0) seedlings treated with either $5 \mu \mathrm{M}$ BAP or $5 \mu \mathrm{M} N A A$ for $0.5 \mathrm{~h}, 1 \mathrm{~h}, 2 \mathrm{~h}, 4 \mathrm{~h}$ and non-treated seedlings as controls. First-strand cDNA was synthesized from total RNA using SuperScript III Reverse Transcriptase (Thermo Fisher Scientific). RT qPCR was performed on CDNAs, with primers spanning an intron summarized in Table 1: for EXPA1 (At1g69530, P1 and P2), EXPA10 (At1g26770, P3 and P4), EXPA14 (At5g56320, P5 and P6) and EXPA15 (At2g03090, P7 and P8). The transcript abundance of EXPAs, relative to constitutively expressed normalizer gene, UBQ10 (At4g05320, P9 and P10), was quantified, using the 2(-Delta Delta C(T)) method (Livak and Schmittgen, 2001) and calibrated to expression at Oh (non-treated). Real-time quantification was performed in Rotor-Gene Q 72-slots using the Rotor-Gene Q Series Software (QIAGEN). PCR conditions were: $95^{\circ} \mathrm{C}$ for $7 \mathrm{~min}$, one cycle; $15 \mathrm{~s}$ at $95^{\circ} \mathrm{C}, 30 \mathrm{~s}$ at $56^{\circ} \mathrm{C}, 30 \mathrm{~s}$ at $72^{\circ} \mathrm{C}, 40$ cycles. 
Reactions with no cDNA monitored for the presence of primer dimers and no reverse transcriptase controls were included for each cDNA sample. PCRs were carried out in triplicate and mean values determined.

\section{Table 1: List of primers used for RT qPCR}

\begin{tabular}{|l|l|l|}
\hline Name & No. & Sequence $\left(\mathbf{5}^{\prime} \mathbf{-} \mathbf{3}^{\prime} \mathbf{)}\right.$ \\
\hline pEXPA1-Fi2 & P1 & CTTACCGAAGAGTGCCGTGCGTG \\
\hline pEXPA1-R2 & P2 & ATTGTCCGTTAAGGTAAGAGTTACTCTG \\
\hline pEXPA10-Fi2 & P3 & CTACAGAAGGGTTCCTTGCAGG \\
\hline pEXPA10-R2 & P4 & TTGCCACACTGTTCTTGAACCCTTG \\
\hline pEXPA14-Fi2 & P5 & AATACCGGAGAGTGGCTTGCCG \\
\hline pEXPA14-R2 & P6 & CGAAGCTCCAGTTACGTGGTGTAGC \\
\hline pEXPA15-Fi2 & P7 & CCTACAGAAGGGTTCCGTGTATG \\
\hline pEXPA15-R2 & P8 & ACGGTACGACCATCACTAGCAGTC \\
\hline UBQ10-F & P9 & AACGGGAAAGACGATTAC \\
\hline UBQ10-R & P10 & ACAAGATGAAGGGTGGAC \\
\hline
\end{tabular}

\section{Cloning and plant transformation}

Standard molecular techniques as described by Ausubel et al., (1999) were used. To clone the translational fusions of expansins with mCherry, firstly, an intermediate clone (pZEOmCherryT35S) that contains unique restriction sites Pacl and SnaBI as well as a flexible linker in front of mCherry sequence, was created as follows. Two DNA fragments were generated by polymerase chain reaction (PCR) using Herculase II Fusion DNA polymerase (Agilent Technologies), primers P11 + P12 and P13 + P14 and plasmids pUCAP-pGEL3::spmCherrypATrpC-BAR (Samalova et al., 2017) and pOpln2 (Samalova et al., 2019) as templates for mCherry and a polyadenylation signal (T35S) respectively. The fragments were joined together by overlapping PCR using P11 and P14. The final product was cloned by BP reaction into attB1 and attB2 sites of GATEWAYTM compatible plasmid pDONOR/Zeo and confirmed by sequencing. Secondly, individual promoter sequences together with EXPA coding sequences (but without a stop codon) were amplified from genomic DNA using primers P15 + P16 (pEXPA1::EXPA1), P17 + P18 (pEXPA10::EXPA10), P19 + P20 (pEXPA14::EXPA14) and P21 + P22 (pEXPA15::EXPA15). The products were digested with either SnaBI (pEXPA1::EXPA1 and pEXPA15::EXPA15), Pacl (pEXPA10::EXPA10) or both Pacl/SnaBI (pEXPA14::EXPA14) and cloned into the same sites of pZEO-mCherryT35S and confirmed by sequencing. Finally, the pEXPA::EXPA:mCherryT35S fusions were re-cloned by LR reaction into attR1 and attR2 sites of pFAST-G01 vector (Shimada et al., 2010).

To overexpress EXPA1 and EXPA1:mCherry fusion, the dexamethasone (Dex) inducible pOp6/LhGR system (Craft et al., 2005; Samalova et al., 2005) was used. Firstly, we PCR-amplified EXPA1 using P23 + P24 and EXPA1:mCherry using P23 + P25 sequences from the pZEOpEXPA1::EXPA1:mCherryT35S vector generated above, cloned into the pDONOR/Zeo vector and confirmed by sequencing. Secondly, using GATAWAYTM cloning strategy described above we re-cloned the EXA1 and EXPA1;mCherry sequences into a pOpln2-RPS5A plasmid 
(Samalova et al., 2019) that drives the LhGR activator under the constitute AtRPS5A promoter (Weijers et al., 2001).

Arabidopsis thaliana (ecotype Columbia-0) was transformed using the floral dip method (Clough and Bent, 1998) and the transgenic plants were selected on Murashige and Skoog (MS) medium (Murashige and Skoog, 1962) containing $15 \mu \mathrm{g} / \mathrm{ml}$ hygromycin for the pFAST-G01 vectors and 10 $\mu \mathrm{g} / \mathrm{ml}$ phosphinothricin for the pOpln2 vectors.

Table 2: List of primers used for expansin cloning - underlined unique restriction sites used for cloning, bold start and stop codons

\begin{tabular}{|l|l|l|}
\hline Name & No. & Sequence (5'- $\mathbf{3}^{\prime}$ ) \\
\hline $\begin{array}{l}\text { attB1-SPS- } \\
\text { mCh-F }\end{array}$ & P11 & $\begin{array}{l}\text { GGGGACAAGTTTGTACAAAAAAGCAGGCTTCCCTGCAGG } \\
\text { ITAATTAAAGGCTACGTAGGAGGCATGGTGAGCAAGGGCG } \\
\text { AGGAGGATAAC }\end{array}$ \\
\hline mCh-T35S-R & P12 & $\begin{array}{l}\text { ATGGTGCGCCAGGAGAGTTGTTGATTACTTGTACAGCTCGT } \\
\text { CCATGCCGC }\end{array}$ \\
\hline mCh-T35S-F & P13 & $\begin{array}{l}\text { GGCATGGACGAGCTGTACAAGTAATCAACAACTCTCCTGG } \\
\text { CGCACCATCG }\end{array}$ \\
\hline attB2-T35S-R & P14 & $\begin{array}{l}\text { GGGGACCACTTTGTACAAGAAAGCTGGGTCCCTGCAGGTC } \\
\text { ACTGGATTTTGGTTTTAGG }\end{array}$ \\
\hline KS-pEXP1-F & P15 & $\begin{array}{l}\text { AAAAGGTACCTACGTAGACAAATGACAATTACTCTTTACGAT } \\
\text { TGTCG }\end{array}$ \\
\hline S-EXP1nos-R & P16 & AAAATACGTAAGC ACTCGAAGCACCACTTCTTTTTAGG \\
\hline KP-pEXP10-F & P17 & $\begin{array}{l}\text { AAAAGGTACCTTAATTAAGTCATCAACAGGTGGATAGTCGC } \\
\text { ATGG }\end{array}$ \\
\hline P-EXP10nos-R & P18 & $\begin{array}{l}\text { AAAATTAATTAAACGGAACTGTCCACCGGCAAAAGTCTGGC } \\
\text { C }\end{array}$ \\
\hline KP-pEXP14-F & P19 & $\begin{array}{l}\text { AAAAGGTACCTTAATTAATTCTTGAATTGATTAAAGTAACGT } \\
\text { GCG }\end{array}$ \\
\hline S-EXP14nos-R & P20 & $\begin{array}{l}\text { AAAATACGTACCTCTGAGCCCGGAACTGTTTTCCGGTATAA } \\
\text { GTC }\end{array}$ \\
\hline KS-pEXP15-F & P21 & $\begin{array}{l}\text { AAAAGGTACCTACGTAAAAACATAATGTCAGAAAAAACATG } \\
\text { GG }\end{array}$ \\
\hline S-EXP15nos-R & P22 & AAAATACGTA ACG GAATTGACGGCCGGTGAAGGTTTGTCC \\
\hline attB1-kExp1-F & P23 & $\begin{array}{l}\text { GGGGACAAGTTTGTACAAAAAAGCAGGCTTCACGATGGCT } \\
\text { CTTGTCACCTTCTTGTTTATTGC }\end{array}$ \\
\hline attB2-smCh-R & P25 & $\begin{array}{l}\text { GGGGACCACTTTGTACAAGAAAGCTGGGTCTTACTTGTACA } \\
\text { GCTCGTCCATGCCGC }\end{array}$ \\
\hline
\end{tabular}




\section{Plant growth condition and dexamethasone (Dex) induction}

Standard MS medium supplemented with 1.5\% sucrose and $0.8 \%$ plant agar (Duchefa), pH 5.8 adjusted by $\mathrm{KOH}$ or $\mathrm{pH} 4$ adjusted by $\mathrm{H}_{2} \mathrm{SO}_{4}$ was used. Plants were cultivated in growth chambers under long day conditions ( $16 \mathrm{~h} \mathrm{light/} 8 \mathrm{~h}$ dark) at $21^{\circ} \mathrm{C}$ in Petri dishes or in soil, with a light intensity of $150 \mu \mathrm{M} \cdot \mathrm{m}^{-2} \cdot \mathrm{s}^{-1}$ and $40 \%$ relative humidity. Unless otherwise stated induction was performed by adding $20 \mu \mathrm{M}$ Dex into the media as described in Samalova et al. (2019). DMSO at the same concentration was used as a control.

\section{Confocal laser scanning microscopy (CLSM) and image analysis}

To localise EXPA:mCherry fusions Zeiss LSM 880 laser-scanning microscope was used. mCherry fluorescence was detected at 580-650 nm with 561-nm HeNe laser excitation and eGFP at 490$550 \mathrm{~nm}$ with a 488-nm Argon laser line. Z-stack projections are shown as maximum intensity. Quantification of the fluorescence was done using CellProfiler (mCherry) and Imaris (nls:3xGFP) softwares. To measure the size of RAM, 7-day old Arabidopsis seedlings were stained with propidium iodide at concentration $30 \mu \mathrm{g} / \mathrm{ml}$ for $5 \mathrm{~min}$, scanned at $590-650 \mathrm{~nm}$ with $488-\mathrm{nm}$ excitation and measured using the ZEN 3.0 software. The roots were imaged using the CApochromat 40x/1.2 water corrected objective lens or Plan-Apochromat 25x/0.8 immersion corrected.

\section{Brillouin light scattering (BLS) microscopy}

Brillouin microscopy was performed using a homebuilt Brillouin confocal microscope described in Elsayad et al., 2016. Excitation was via a single-mode 532nm laser (Torus, Laser Quantum, DE). A dual cross-dispersion Virtual Imaged Phase Array (VIPA) spectrometer (Scarcelli et al., 2015) with a Lyott Stop (Edrei et al., 2017) was employed for measuring the Brillouin Light Scattering spectra. The spectral projection was measured on a cooled EM CCD camera (ImageEMX II, Hamamatsu, JP). The spectrometer was coupled to an inverted microscope frame (IX73, Olympus, JP) via a physical pinhole with an effective size of 1 Airy Unit to assure optimum confocal detection. After the pinhole a dichroic mirror was used to outcouple light with wavelengths longer than $536 \mathrm{~nm}$ to a fluorescence spectrometer (Ocean Optics QE Pro, USA) to detect the fluorescence signal assuring pixel-to-pixel correlation with the measured Brillouin spectra. To acquire Brillouin maps, samples were scanned in $x, y$ \&/or $z$ using either a 3-axis long-range Piezostage (Physik Instrumente, DE) or a motor stage (ASI, USA), both mounted on top of the inverted microscope frame. Light could also be coupled out through a second port on the microscope frame using a long-pass filter (AHF, DE) and tube lens to a compact sCMOS camera (Thorlabs, DE) allowing us to locate samples and regions of interest (in wide-field transmitted light conditions when illuminating sample from the top with a Halogen lamp) as well as monitor the position being probed during scanning.

All hardware was controlled using LabView (National Instruments, USA) based software developed by the company THATec (DE) especially for our microscope. The 16bit depth spectral projection image for each position in a spatial scan was exported from the native THATec format into Matlab (Mathworks, DE), where a custom written code was used for analysis. This code (see also Elsayad et al., 2016) used two calibration spectra (of triple distilled water and spectroscopic grade ethyl alcohol) measured before and after each set of scans. These were used for registration 
of the spectral projection onto a frequency scale, based on the calculated disperion for a dualVIPA setup in the paraxial approximation regime (Xiao et al., 2014). The alignment of the spectrometer was such that maximal energy was transferred into a single diffraction order. Due to the spatial masking of the elastic scattering peaks at the two intermediate imaging planes in the spectrometer, the spectral projection consisted of only two inelastic scattering peaks corresponding to the so-called Brillouin Stokes and anti-Stokes scattering peaks.

All data analysis was performed in Matlab (Mathworks, DE) using custom written scripts (Elsayad et al., 2016). Spectral phasor analysis (Elsayad, 2019) was used to obtain initial parameter estimates for peak positions and widths which were subsequently inserted into a non-linear least squares fitting algorithm that fitted two broadened Lorentzian functions (Voigt functions) to obtain the two peak positions, from which the Brillouin frequency shift could be obtained. The BLS spectra was also deconvolved in phasor space using a response function obtained from measuring the attenuated Rayleigh scattering inside the respective samples (by opening the spatial masks).

For all scans the laser power at the sample was between 1-5 mW, and the dwell time per point, which was also the acquisition time of each spectra, was $100 \mathrm{~ms}$. Cells were observed (by transmitted-light widefield illumination) to appear healthy and unperturbed after experiments, suggesting the BLS measurements had no negative or phototoxic effects. A 1.4 NA objective was used for excitation and detection (back-scattering geometry). As such a broad range of scattering wavevectors is probed and one effectively probes directionally averaged elastic moduli. As a direct consequence of probing a broad spectrum of wavevectors, the Brillouin spectra is broadened as predicted from the momentum-energy conservation equations describing the scattering processes. The so-called Brillouin scattering peak position is however not noticeably modified to within experimental uncertainties, as was verified by reducing the numerical aperture of excitation and detection on the studied samples using an iris in the beam path.

Roots of 7-day old Arabidopsis seedlings were scanned at the early EZ, the size of the scan was $25 \mathrm{um} \times 25$ um (50 x 50 pixels), step size typically $500 \mathrm{~nm}$ (or $250 \mathrm{~nm}$ for larger scans) using the piezo-stage.

\section{Refractive index tomography}

Refractive index tomograms were acquired on a holotomographic microscope with rotational scanning 3D Cell Explorer (Nanolive SA, Lausanne, Switzerland) with Nikon BE Plan 60x NA 0.8. The size of acquired tomogram was $93.1 \times 93.1 \times 35.7 \mu \mathrm{m}(x y z)$. Samples were measured in water (reference refractive index 1.330). Software Steve 1.6.3496 (Nanolive SA) was used for image acquisition. Subsequent image analysis was performed in ImageJ 1.52q (NIH, USA) on a max projection of tomography data. Following parameters were extracted: mean refractive index at cell wall of longitudinal and transverse axes of cell.

\section{Atomic force microscopy (AFM)}

Roots of 7-day old Arabidopsis seedlings were immobilized on glass slides and surrounded by stiff agarose. Approximate early EZ was defined based on the visual landmark observed through a bright field microscope. In order to extract the mechanical properties of only the outer cell wall, the maximum indentation force was set to $60 \mathrm{nN}$ to archive a maximum indentation of no more 
than $80 \mathrm{~nm}$. The cantilever used was "Nano World" (Nanosensors Headquarters, Neuchâtel, Switzerland) SD-R150-T3L450B tips with a spring constant of $0.15-1.83 \mathrm{~N} / \mathrm{m}$ (the one used was estimated to be $0.781 \mathrm{~N} / \mathrm{m}$ ) with silicon point probe tips of a $150-\mathrm{nm}$ radius.

All force spectroscopy experiments were performed as previously described (Feng et al., 2018; Peaucelle, 2014; Peaucelle et al., 2015). Briefly, stiffness of samples was determined as follows: an AFM cantilever loaded with a spherical tip was used to indent the sample over a $60 \times 100 \mu \mathrm{m}$ square area, within the area $60 \times 100$ measurements were made resulting in 6000 forceindentation experiments; each force-indentation experiment was treated with a Hertzian indentation model to extract the apparent Young's modulus (EA); each pixel in a stiffness map represents the apparent Young's modulus from one force-indentation point. The EA was calculated using the JPK Data Processing software (ver. Spm - 4.0.23, JPK Instruments AG, Germany), which allows for a more standardized analysis than the estimation of the EA using a standard Hertzian contact model (Peaucelle, 2014; Peaucelle et al., 2015). Only the retraction curve was used in our analyses as is typically the case in nano-indentation experiments. A Poisson ratio of 0.5 was assumed for the material. Range distribution of $\mathrm{E}_{\mathrm{A}}$ from $0.2 \mathrm{MPa}$ to $3 \mathrm{MPa}$ in $1-\mathrm{MPa}$ binned groups was calculated using MATLAB.

\section{Statistical analysis}

For statistical analyses simple ANOVA and post-hoc Tukey test was used. For pairwise comparisons in repeated experiments, mixed model ANOVA using random effects for the different experiments was used with Tukey test as a post-hoc test. In case of non-normal count data (e.g No. of cells) a Poisson mixed model was used to identify differences between genotypes. For the implementation of the mixed models the Ime4 package in $\mathrm{R}$ was used (Bates et al., 2015).

\section{REFERENCES}

Andriotis, O.G., Elsayad, K., Smart, D.E., Nalbach, M., Davies, D.E. and Thurner, P.J. (2019) Hydration and nanomechanical changes in collagen fibrils bearing advanced glycation endproduct. Biomed Opt Express 10:1841-1855.

Antonacci, G., Beck, T., Bilenca, A., Czarske, J., Elsayad, K., Guck, J., Kim, K., Krug, B., Palombo, F., Prevedel, R. and Scarcelli, G. (2020) Recent progress and current opinions in Brillouin microscopy for life science applications. Biophysical Reviews 12: 615-624.

Ausubel, F., Brent, R., Kingston, R.E., Moore, J.G., Seidman, J.G., Smith, J.A., Struhl, J.G. eds. (1999) In Current Protocols in Molecular Biology, New York: John Wiley.

Balestrini, R., Cosgrove, D.J. and Bonfante, P. (2005) Differential location of alpha-expansin proteins during the accommodation of root cells to an arbuscular mycorrhizal fungus. Planta 220: 889-899.

Bates, D., Mächler, M., Bolker, B. and Walker, S. (2015) Fitting linear mixed-effects models using Ime4. Journal of Statistical Software, 67: 1-48. 
Barbez, E., Dunser, K., Gaidora, A., Lendl, T. and Busch, W. (2017) Auxin steers root cell expansion via apoplastic $\mathrm{pH}$ regulation in Arabidopsis thaliana. Proc Natl Acad Sci 114: E4884E4893.

Berne, B.J. and Pecora, R. eds. (2000) Dynamic light scattering, with applications to chemistry, biology, and physics. New York, NY: Dover Publications.

Bhargava, A., Clabaugh, I., To, J.P., Maxwell, B.B., Chiang, Y.-H., Schaller, G.E., Loraine, A. and Kieber, J.J. (2013) Identification of cytokinin-responsive genes using microarray metaanalysis and RNA-Seq in Arabidopsis. Plant Physiol 162: 272-29.

Braybrook, S. and Jönsson, H. (2016) Shifting foundations: the mechanical cell wall and development. Curr Opin Plant Biol 29: 115-120.

Braybrook, S.A. and Peaucelle, A. (2013) Mechano-Chemical aspects of organ formation in Arabidopsis thaliana: The relationship between auxin and pectin. Plos One 8.

Caderas, D., Muster, M., Vogler, H., Mandel, T., Rose, J.K.C., McQueen-Mason, S. and Kuhlemeier, C. (2000) Limited correlation between expansin gene expression and elongation growth rate. Plant Physiol 123: 1399-1413.

Cho, H.-T. and Cosgrove, D.J. (2000) Altered expression of expansin modulates leaf growth and pedicel abscission in Arabidopsis thaliana. Proc Natl Acad Sci 97: 9783-9788.

Cho, H.-T. and Cosgrove, D. J. (2002) Regulation of root hair initiation and expansin gene expression in Arabidopsis. Plant Cell 14: 3237-53.

Cho, H.-T. and Kende, H. (1998) Tissue localization of expansins in deepwater rice. Plant J 15: 805-812.

Choi, D.S., Lee, Y., Cho, H.-T. and Kende, H. (2003) Regulation of expansin gene expression affects growth and development in transgenic rice plants. Plant Cell 15: 1386-1398.

Cleland, R. (1971) Cell wall extension. Ann Rev Plant Physiol 22: 197-222.

Clough, S.J. and Bent, A.F. (1998) Floral dip: a simplified method for Agrobacterium-mediated transformation of Arabidopsis thaliana. Plant J 16: 735-43.

Cosgrove, D.J., Li, L.C., Cho, H.-T., Hoffmann-Benning, S., Moore, R.C. and Blecker, D. (2002) The growing world of expansins. Plant Cell Physiol 43: 1436-1444.

Cosgrove, D.J. (2005) Growth of the plant cell wall. Nat Rev Mol Cell Biol 6: 850-861.

Cosgrove, D.J. (2014) Re-constructing our models of cellulose and primary cell wall assembly. Curr Opin Plant Biol 22: 122-131.

Cosgrove, D.J. (2018) Nanoscale structure, mechanics and growth of epidermal cell walls. Curr Opin Plant Biol 46: 77-86.

Cosgrove, D.J. (2018b) Diffuse growth of plant cell walls. Plant Physiol 176: 16-27. 
Craft, J., Samalova, M., Baroux, C., Townley, H., Martinez, A., Jepson, I., Tsiantis, M. and Moore, I. (2005) New pOp/LhG4 vectors for stringent glucocorticoid-dependent transgene expression in Arabidopsis. Plant J 41: 899-918.

Dello loio, R., Linhares, F.S., Scacchi, E., Casamitjana-Martinez, E., Heidstra, R., Costantino, P. and Sabatini, S. (2007) Cytokinins determine Arabidopsis root-meristem size by controlling cell differentiation. Curr Biol 17: 678-682.

Dello loio, R., Linhares, F.S. and Sabatini, S. (2008) Emerging role of cytokinin as a regulator of cellular differentiation. Curr Opin Plant Biol 11: 23-27.

Didi, V., Jackson, P. and Hejatko, J. (2015) Hormonal regulation of secondary cell wall formation. J Exp Bot 66: 5015-27.

Di Mambro, R., De Ruvo, M., Pacifici, E., Salvi, E., Sozzani, R., Benfey, P.N., Busch, W., Novak, O., Ljung, K., Di Paola, L., Marée, A.F.M., Costantino, P., Grieneisen, V.A. and Sabatini, S. (2017) Auxin minimum triggers the developmental switch from cell division to cell differentiation in the Arabidopsis root. Proc Natl Acad Sci 114: E7641-E7649.

Di Mambro, R., Svolacchia, N., Dello loio, R., Pierdonati, E., Salvi, E., Pedrazzini, E., Vitale, A., Perilli, S., Sozzani, R., Benfey, P.N., Busch, W., Costantino, P. and Sabatini, S. (2019) The lateral root cap acts as an auxin sink that controls meristem size. Curr Biol 29: 1199-1205.

Edrei, E., Gather, M.C. and Scarcelli, G. (2017) Adaptive optics in spectroscopy and densely labeled-fluorescence applications. Optics Express 26: 33865-33877.

Elsayad, K., Werner, S., Gallemí, M., Kong, J., Sánchez Guajardo, E.R., Zhang, L., Jaillais, Y., Greb, T. and Belkhadir, Y. (2016) Mapping the subcellular mechanical properties oflive cells in tissues with fluorescence emission-Brillouin imaging. Science Signaling 435: rs5.

Elsayad, K. (2019) Spectral phasor analysis for Brillouin microspectroscopy. Front Phys 7:62.

Elsayad, K., Polakova, S. and Gregan, J. (2019) Probing mechanical properties in biology using Brillouin microscopy. Trends in Cell Biol 8: 608-611.

Engler, A.J., Sen, S., Sweeney, H.L. and Discher, D.E. (2006) Matrix elasticity directs stem cell lineage specification Cell 126: 677-689.

Feng, W., Kita, D., Peaucelle, A., Cartwright, H.N., Doan, V., Duan, Q., Liu, M.C., Maman, J., Steinhorst, L., Schmitz-Thom, I., Yvon, R., Kudla, J., Wu, H.M., Cheung, A.Y. and Dinneny, J.R. (2018) The FERONIA receptor kinase maintains cell-wall integrity during salt stres through Ca2+ signaling. Curr Biol 28: 666-675.

Fleming, A. J., McQueen-Mason, S., Mandel, T. and Kuhlemeier, C. (1997) Induction of leaf primordia by the cell wall protein expansin. Science 276: 1415-1418.

Freese, N.H., Norris, D.C. and Loraine, A.E. (2016) Integrated Genome Browser: Visual analytics platform for genomics. Bioinformatics 32: 2089-2095.

Geitmann, A. and Ortega, J.K.E. (2009) Mechanics and modeling of plant cell growth. Trends Plant Sci 14: 467-478. 
Georgelis, N., Tabuchi, A., Nikolaidis, N. and Cosgrove, D.J. (2011) Structure-function analysis of the bacterial expansin EXLX1. J Biol Chem 286: 16814-16823.

Gigli-Bisceglia, N., Engelsdorf, T., Strnad, M., Vaahtera, L., Khan, G.A., Yamoune, A., Alipanah, L., Novak, O., Persson, S., Hejatko, J. and Hamann, T. (2018) Cell wall integrity modulates Arabidopsis thaliana cell cycle gene expression in a cytokinin- and nitrate reductasedependent manner. Development 145: dev166678.

Goh, H.H., Sloan, J., Malinowski, R. and Fleming, A. (2014) Variable expansin expression in Arabidopsis leads to different growth responses. J Plant Physiol 171: 329-339.

Gouveia, R.M., Lepert, G., Gupta, S., Mohan, R.R., Paterson, C. and Connon, C.J. (2019) Assessment of corneal substrate biomechanics and its effect on epithelial stem cell maintenance and differentiation. Nat Commun 10: 1496.

Gruel, J., Landrein, B., Tarr, P., Schuster, C., Refahi, Y., Sampathkumar, A., Hamant, O., Meyerowitz, E.M. and Jonsson, H. (2016) An epidermis-driven mechanism positions and scales stem cell niches in plants. Sci Adv 2: e1500989.

Haas, K.T., Wightman, R., Meyerowitz, E.M. and Peaucelle, A. (2020) Pectin homogalacturonan nanofilament expansion drives morphogenesis in plant epidermal cells. Science 367: 1003-1007.

Hager, A., Menzel, H. and Krauss, A. (1971) Versuche und Hypothese zur Primarwirkung des Auxin beim Streckungswachtum. Planta 100: 47-75.

Hamant, O., Heisler, M.G., Jonsson, H., Krupinski, P., Uyttewaal, M., Bokov, P., Corson, F., Sahlin, P., Boudaoud, A., Meyerowitz, E.M., Couder, Y. and Traas, J. (2008) Developmental patterning by mechanical signals in Arabidopsis. Science 322: 1650-1655.

Hamant, O. and Traas, J. (2010) The mechanics behind plant development. New Phytol 185: 369-385.

Hamant, O., Inoue, D., Bouchez, D., Dumais, J. and Mjolsness, E. (2019) Are microtubules tension sensors? Nat Commun 10: 2360.

Hervieux, N., Tsugawa, S., Fruleux, A., Dumond, M., Routier-Kierzkowska, A.L., Komatsuzaki, T., Boudaoud, A., Larkin, J.C., Smith, R.S., Li, C.B. and Hamant, O. (2017) Mechanical shielding of rapidly growing cells buffers growth heterogeneity and contributes to organ shape reproducibility. Curr Biol 27: 3468-3479.

Hurny, A., Cuesta, C., Cavallari, N., Otvos, K., Duclercq, J., Dokladal, L., Montesinos, J.C., Gallemi, M., Semeradova, H., Rauter, T., Stenzel, I., Persiau, G., Benade, F., Bhalearo, R., Sykorova, E., Gorzsas, A., Sechet, J., Mouille, G., Heilmann, I., De Jaeger, G., Ludwig-Muller, J. and Benkova, E. (2020) SYNERGISTIC ON AUXIN AND CYTOKININ 1 positively regulates growth and attenuates soil pathogen resistance. Nat Commun 11: 2170.

Ilias, I.A., Negishi, K., Yasue, K., Jomura, N., Morohashi, K., Baharum, S. N. and Goh, H.-H. (2019) Transcriptome-wide effects of expansin gene manipulation in etiolated Arabidopsis seedling. J Plant Res132: 159-172. 
Landrein, B., Kiss, A., Sassi, M., Chauvet, A., Das, P., Cortizo, M., Laufs, P., Takeda, S., Aida, M., Traas, J., Vernoux, T., Boudaoud, A. and Hamant, O. (2015) Mechanical stress contributes to the expression of the STM homeobox gene in Arabidopsis shoot meristems. eLife 4: e07811.

Lee, D.J., Park, J.-Y., Ku, S.-J., Ha, J.-M., Kim, S., Kim, M.D., Oh, M.-H. and Kim, J. (2007) Genome-wide expression profiling of ARABIDOPSIS RESPONSE REGULATOR 7 (ARR7) overexpression in cytokinin response. Mol Genet Genom 277: 115-137.

Lee, H.W. and Kim, J. (2013) EXPANSINA17 up-regulated by LBD18/ASL20 promotes lateral root formation during the auxin response. Plant Cell Physiol 54: 1600-11.

Li, Y., Darley, C.P., Ongaro, V., Fleming, A., Schipper, O., Baldauf, S.L. and McQueenMason, S.J. (2002) Plant expansins are a complex multigene family with an ancient evolutionary origin. Plant Physiol 128: 854-864.

Livak, K.J. and Schmittgen, T.D. (2001) Analysis of relative gene expression data using realtime quantitative PCR and the 2(-Delta Delta C(T)) method. Methods 25: 402-408.

Majda, M., Grones, P., Sintorn, I.M., Vain, T., Milani, P., Krupinski, P., Zagorska-Marek, B., Viotti, C., Jonsson, H., Mellerowicz, E.J., Hamant, O. and Robert, S. (2017) Mechanochemical polarization of contiguous cell walls shapes plant pavement cells. Dev Cell 43: 290-300.

McQueen-Mason, S., Durachko, D.M. and Cosgrove, D.J. (1992) Two endogenous proteins that induce cell wall extension in plants. Plant Cell 4:1425-33.

McQueen-Mason, S. and Cosgrove, D.J. (1994) Disruption of hydrogen bonding between plant cell wall polymers by proteins that induce wall extension. Proc Natl Acad Sci 91: 6574-6578.

McQueen-Mason S. and Cosgrove, D.J. (1995) Expansin mode of action on cell walls: analysis of wall hydrolysis, stress relaxation, and binding. Plant Physiol 107: 87-100.

Murashige, T. and Skoog, F. (1962) A revised medium for rapid growth and bioassays with tobacco tissue. Physiol Plant 15: 493-497.

O'Malley, R.C., Huang, S.C., Song, L., Lewsey, M.G., Bartlett, A., Nery, J.R., Galli, M., Gallavotti, A. and Ecker, J.R. (2016) Cistrome and epicistrome features shape the regulatory DNA landscape. Cell 165:1280-1292.

Pacifici, E., Di Mambro, R., Dello loio, R., Costantino, P. and Sabatini, S. (2018) Acidic cell elongation drives cell differentiation in the Arabidopsis root. EMBO J 37: e99134.

Palombo, F., Winlove, C.P., Edginton, R.S., Green, E., Stone, N., Caponi, S., Madami, M. and Fioretto, D. (2014) Biomechanics of fibrous proteins of the extracellular matrix studied by Brillouin scattering. J Royal Society Interface 11: 20140739.

Park, S. H., Li, F., Renaud, J., Shen, W., Li, Y., Guo, L., Cui, H., Sumarah, M. and Wang, A. (2017) NbEXPA1, an $\alpha$-expansin, is plasmodesmata-specific and a novel host factor for potyviral infection. Plant J 92: 846-886. 
Peaucelle, A., Louvet, R., Johansen, J.N., Höfte, H., Laufs, P., Pelloux, J. and Mouille, G. (2008) Arabidopsis phyllotaxis is controlled by the methyl-esterification status of cell-wall pectins. Curr Biol 18: 1943-1948.

Peaucelle, A., Braybrook, S.A., Le Guillou, L., Bron, E., Kuhlemeier, C. and Höfte, H. (2011) Pectin-induced changes in cell wall mechanics underlie organ initiation in Arabidopsis. Curr Biol 21: $1720-1726$.

Peaucelle, A. (2014) AFM-based mapping of the elastic properties of cell walls: at tissue, cellular, and subcellular resolutions. J Vis Exp 89: 51317.

Peaucelle, A., Wightman, R. and Höfte, H. (2015) The control of growth symmetry breaking in the Arabidopsis hypocotyl. Curr Biol 25:1746-1752.

Pien, S., Wyrzykowska, J., McQueen-Mason, S., Smart, C. and Fleming, A. (2001) Local expression of expansin induces the entire process of leaf development and modifies leaf shape. Proc Natl Acad Sci 98: 11812-11817.

Prevedel, R., Diz-Munoz, A., Ruocco, G. and Antonacci, G. (2019) Brillouin microscopy: an emerging tool for mechanobiology. Nat Methods 16: 969-977.

Ramakrishna, P., Ruiz Duarte, P., Rance, G.A., Schubert, M., Vordermaier, V., Dai Vue, L., Murphy, E., Vilches Barro, A., Swarup, K., Moirangthema, K., Jørgenseni, B., van de Cotte, B., Goh, T., Lin, Z., Voss, U., Beeckman, T., Bennett, M.J., Gevaert, K., Maizel, A. and De Smet, I. (2019) EXPANSIN A1-mediated radial swelling of pericycle cells positions anticlinal cell divisions during lateral root initiation. Proc Natl Acad Sci 116: 8597-8602.

Rebocho, A.B., Southam, P., Kennaway, J.R., Bangham, J.A. and Coen, E. (2017) Generation of shape complexity through tissue conflict resolution. eLife 6: e20156.

Reinhardt, D., Wittwer, F., Mandel, T. and Kuhlemeier, C. (1998) Localized upregulation of a new expansin gene predicts the site of leaf formation in the tomato meristem. Plant Cell 10: 14271437.

Ribas, A., Volpi de Silva, N., Santos, T., Abrantes, F., Custodio, C., Machado Neto, N. and Vieira, L. (2019). Regulation of a-expansins genes in Arabidopsis thaliana seeds during postosmopriming germination. Physiol Mol Biol Plants 25: 511-522.

Sanchez-Montesino, R., Bouza-Morcillo, L., Marquez, J., Ghita, M., Duran-Nebreda, S., Gomez, L., Holdsworth, M.J., Basse, I.G. and Onate-Sanchez, L. (2019) A regulatory module controlling GA-mediated endosperm cell expansion is critical for seed germination in Arabidopsis. Mol Plant 12: 71-85.

Samalova, M., Brzobohaty, B. and Moore, I. (2005) pOp6/LhGR: a stringently regulated and highly responsive dexamethasone-inducible gene expression system for tobacco. Plant J 41: 919935.

Samalova, M., Melida, H., Vilaplana, F., Bulone, V., Soanes, D.M., Talbot, N.J. and Gurr, S.J. (2017) The $\beta$-1,3-glucanosyltransferases (Gels) affect the structure of the rice blast fungal cell wall during appressorium-mediated plant infection. Cell Microbiol 19: e12659. 
Samalova, M., Kirchhelle, C. and Moore, I. (2019) Universal methods for transgene induction using the dexamethasone-inducible transcription activation system pOp6/LhGR in Arabidopsis and other plant species. Current Protocols in Plant Biol 4: e20089.

Sampathkumar, A., Krupinski, P., Wightman, R., Milani, P., Berquand, A., Boudaoud, A., Hamant, O., Jonsson, H. and Meyerowitz, E.M. (2014) Subcellular and supracellular mechanical stress prescribes cytoskeleton behavior in Arabidopsis cotyledon pavement cells. eLife 3: e01967.

Sampedro, J. and Cosgrove, D.J. (2005) The expansin superfamily. Genome Biol 6: 242.

Sassi, M. and Trass, J. (2015) When biochemistry meets mechanics: a systems view of growth control in plants. Curr Opin Plant Biol 28: 137-143.

Scarcelli, G. and Yun, S.H. (2007) Confocal Brillouin microscopy for three-dimensional mechanical imaging. Nat Photonics 2: 39-43.

Scarcelli, G., Polacheck, W.J., Nia, H.T., Patel., K., Grodzinsky, A.J., Kamm, R.D. and Yun, S.H. (2015) Noncontact three-dimensional mapping of intracellular hydromechanical properties by Brillouin microscopy. Nat Methods 12: 1132-1134.

Shaner, N.C., Campbell, R.E., Steinbach, P.A., Giepmans, B.N.G., Palmer, A.E. and Tsien, R.Y. (2004) Improved monomeric red, orange and yellow fluorescent proteins derived from Discosoma sp. red fluorescent protein. Nat Biotechnol 22: 1567-1572.

Shimada, T. L., Shimada, T. and Hara-Nishimura, I. (2010) A rapid and non-destructive screenable marker, FAST, for identifying transformed seeds of Arabidopsis thaliana. Plant J 61: 519-528.

Takatani, S., Verger, S., Okamoto, T., Takahashi, T., Hamant, O. and Motose, H. (2020) Microtubule response to tensile stress is curbed by NEK6 to buffer growth variation in the Arabidopsis hypocotyl. Curr Biol 30: 1491-1503.

Takatsuka, H., Higaki, T. and Umeda, M. (2018) Actin reorganization triggers rapid cell elongation in roots. Plant Physiol 178: 1130-1141.

Taniguchi, M., Sasaki, N., Tsuge, T., Aoyama, A. and Oka, A. (2007) ARR1 directly activates cytokinin response genes that encode proteins with diverse regulatory functions. Plant Cell Physiol 48: 263-277.

Uyttewaal, M., Burian, A., Alim, K., Landrein, B., Borowska-Wykret, D., Dedieu, A., Peaucelle, A., Ludynia, M., Traas, J., Boudaoud, A., Kwiatkowska, D. and Hamant, O. (2012) Mechanical stress acts via katanin to amplify differences in growth rate between adjacent cells in Arabidopsis. Cell 149: 439-451.

Vermeer, J.E., von Wangenheim, D., Barberon, M., Lee, Y., Stelzer, E.H., Maizel, A. and Geldner, N. (2014) A spatial accommodation by neighboring cells is required for organ initiation in Arabidopsis. Science 343: 178-183.

Vogler, H., Caderas, D., Mandel, T. and Kuhlemeier, C. (2003) Domains of expansin gene expression define growth regions in the shoot apex of tomato. Plant Mol Biol 53: 267-272. 
Wang, X. and Cosgrove, D.J. (2020) Pectin methylesterase selectively softens the onion epidermal wall yet reduces acid-induced creep. J Exp Bot 71: 2629-2640.

Wang, T., Park, Y.B., Caporini, M.A., Rosay, M., Zhong, L., Cosgrove, D.J. and Hong, M. (2013) Sensitivity-enhanced solid-state NMR detection of expansin's target in plant cell walls. Proc Natl Acad Sci 110: 16444-16449.

Weijers D., Franke-van Dijk, M., Vencken, R. J., Quint, A., Hooykaas, P. and Offringa, R. (2001) An Arabidopsis Minute-like phenotype caused by a semi-dominant mutation in a RIBOSOMAL PROTEIN S5 gene. Development 128: 4289-4299.

Willis, L., Refahi, Y., Wightman, R., Landrein, B., Teles, J., Huang, K.C., Meyerowitz, E.M. and Jönsson, H. (2016) Cell size and growth regulation in the Arabidopsis thaliana apical stem cell niche. Proc Natl Acad Sci 113: E8238-E8246.

Wolf, S., Hematy, K. and Hofte, H. (2012) Growth control and cell wall signaling in plants. Annu Rev Plant Biol 63: 381-407.

Wu, P.-J., Kabakova, I.V., Ruberti, J.W., Sherwood, J.M., Dunlop, I.E., Paterson, C., Torok, P. and Overby, D.R. (2018) Water content, not stiffness, dominates Brillouin spectroscopy measurements in hydrated materials. Nat Methods 15: 561-562.

Xiao et al. IEEE Journal of Quantum Electronics (2014)

Xie, M., Chen, H., Huang, L., O'Neil, R.C., Shokhirev, M.N. and Ecker, J.R. (2018) A B-ARRmediated cytokinin transcriptional network directs hormone cross-regulation and shoot development. Nat Commun 9:1604.

Yang, C., DelRio, F.W., Ma, H., Killaars, A.R., Basta, L.P., Kyburz, K.A. and Anseth, K.S. (2016) Spatially patterned matrix elasticity directs stem cell fate. Proc Natl Acad Sci 113: E44394445.

Yuan, S., Wu, Y. and Cosgrove, D.J. (2001) A fungal endoglucanase with plant cell wall extension activity. Plant Physiol 127: 324-333.

Zenoni, S., Fasoli, M., Tornielli, G.B., Dal Santo, S., Sanson, A., de Groot, P., Sordo, S., Citterio, S., Monti, F. and Pezzotti, M. (2011) Overexpression of PhEXPA1 increases cell size, modifies cell wall polymer composition and affects the timing of axillary meristem development in Petunia hybrida. New Phytol 191: 662-677.

Zhang, N. and Hasenstein, K.H. (2000) Distribution of expansins in graviresponding maize roots. Plant Cell Physiol 41: 1305-1312.

Zhang, T., Mahgsoudy-Louyeh, S., Tittmann, B. and Cosgrove, D.J. (2014) Visualization of the nanoscale pattern of recently-deposited cellulose microfibrils and matrix materials in neverdried primary walls of the onion epidermis. Cellulose 21: 853-862.

Zhao, H., Brown, P.H. and Schuck, P. (2011) On the distribution of protein refractive index increments. Biophys J 100: 2309-2317.

Zubo, Y.O, Clabaugh Blakley, I., Yamburenko, M.V., Worthen, J.M., Street, H.S., FrancoZorrilla, J.M., Zhang, W., Hill, K., Raines, T., Solano, S., Kieber, J.J., Loraine, A.E. and 
bioRxiv preprint doi: https://doi.org/10.1101/2020.06.25.170969; this version posted July 31, 2020. The copyright holder for this preprint (which was not certified by peer review) is the author/funder, who has granted bioRxiv a license to display the preprint in perpetuity. It is made available under aCC-BY-NC-ND 4.0 International license.

Schaller, G.E. (2017) Cytokinin induces genome-wide binding of the type-B response regulator ARR10 to regulate growth and development in Arabidopsis. Proc Natl Acad Sci 114: E5995E6004. 


\section{SUPPLEMENTARY FIGURES AND FIGURE LEGENDS}
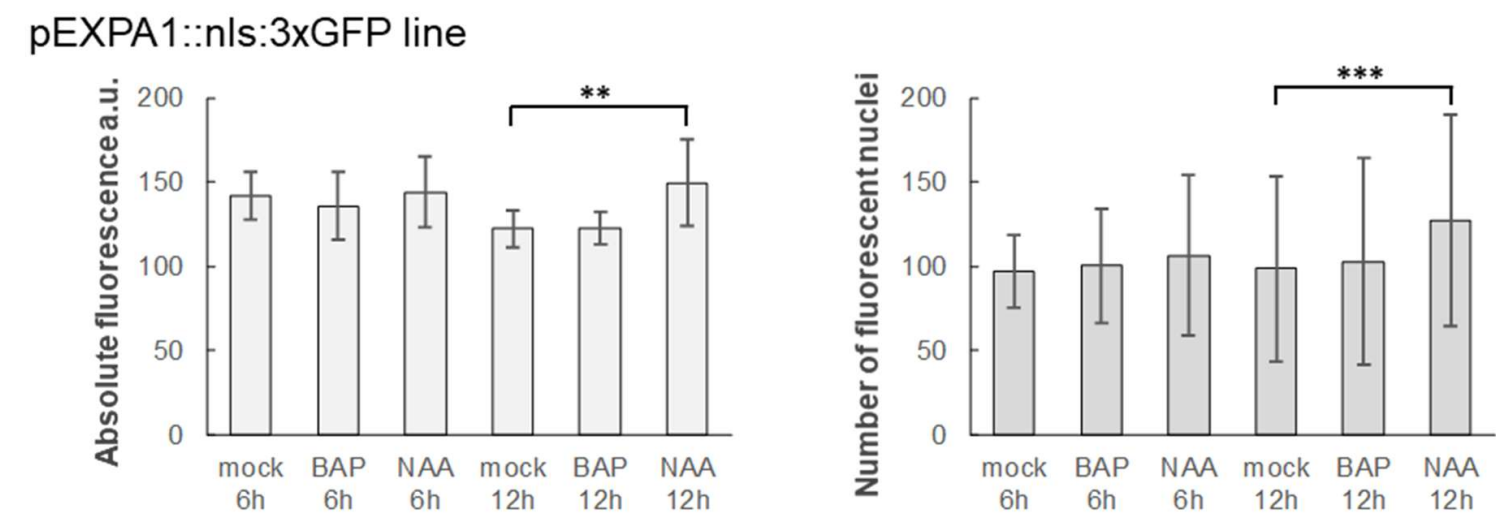

Figure 1 - Figure Supplement 1: EXPA1 is not inducible by cytokinins in the root tip.

7-day old Arabidopsis seedlings of pEXPA1::nls:3xGFP line were treated with $5 \mu \mathrm{M}$ BAP and 5 $\mu \mathrm{M}$ NAA for $6 \mathrm{~h}$ and $12 \mathrm{~h}$. Absolute fluorescence (left) and a number of fluorescent nuclei (right) was quantified from 3D confocal z-stacks using IMARIS software. 8-10 seedlings were used in each category, average and SD were calculated and displayed in the graphs. Statistically significant differences at alpha $0.01\left(^{* *}\right)$ and $0.001\left(^{(* *}\right)$ are shown. 
bioRxiv preprint doi: https://doi.org/10.1101/2020.06.25.170969; this version posted July 31, 2020. The copyright holder for this preprin (which was not certified by peer review) is the author/funder, who has granted bioRxiv a license to display the preprint in perpetuity. It is made available under aCC-BY-NC-ND 4.0 International license.

\section{A pEXPA1::nls:3xGFP}
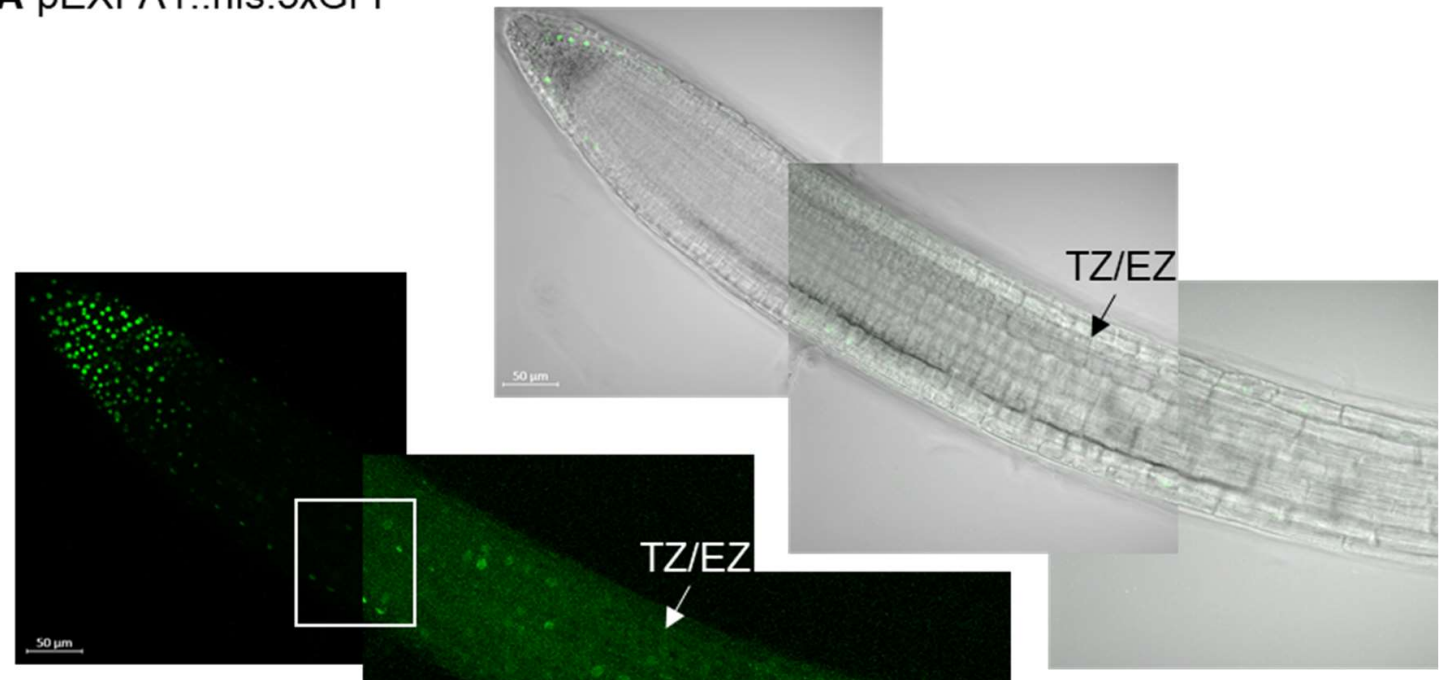

Enhanced image

\section{B pEXPA1::EXPA1:mCherry}

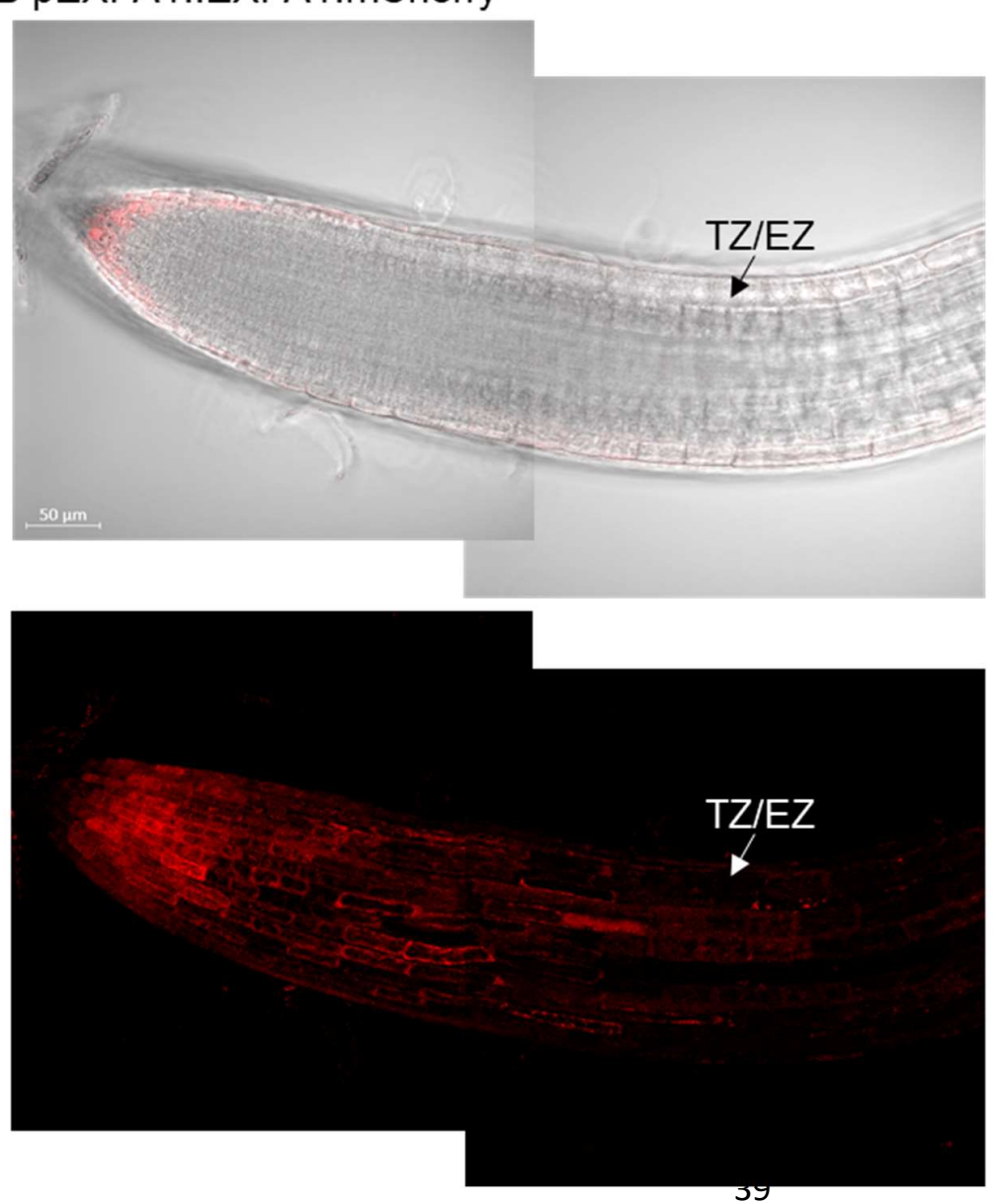


Figure 1 - Figure Supplement 2: EXPA1 activity is only occasionally detectable in the root TZ while EXPA1 signal is delimited to the columella/lateral root cap.

Z-stack projections and transmitted-light micrographs shown as a single optical section of 7-day old Arabidopsis seedlings of (A) pEXPA1::n/s:3xGFP and (B) pEXPA1::EXPA1:mCherry lines. The TZ/EZ boundary is depicted (arrow). The white square marks the same root area visualised without and with image enhancement done using the CLSM Zen 3.0 software.

TF of cytokinin signalling

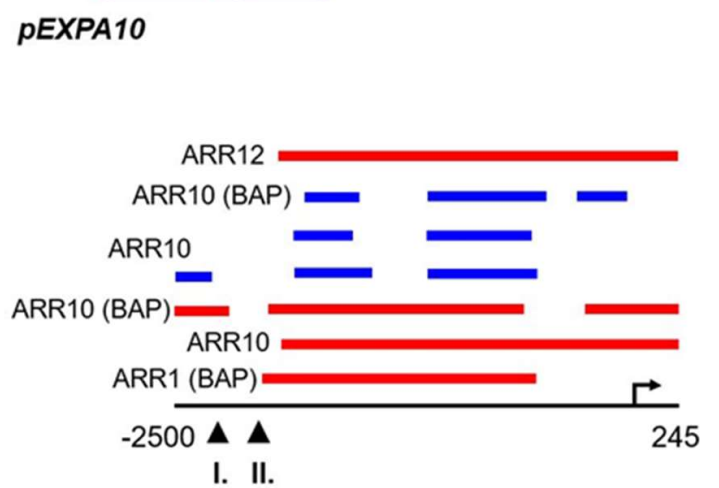

pEXPA14

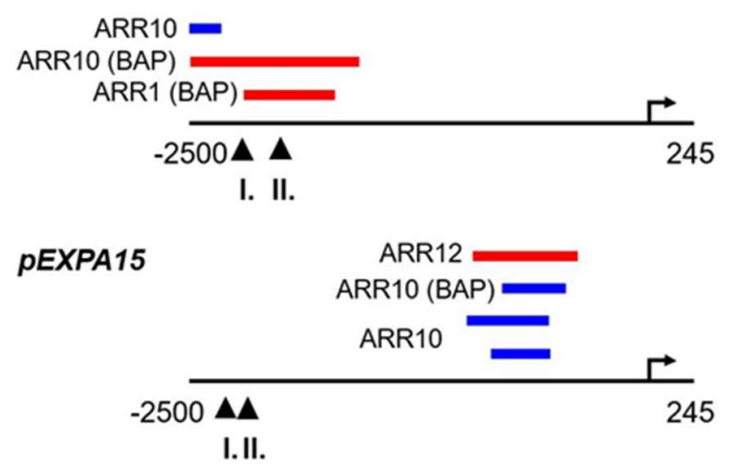

Figure 2 - Figure Supplement 1: Cytokinin-responsive transcription factors bind to EXPA promoters.

Promoter analysis of EXPA10, EXPA14 and EXPA15 identifies ChIP-seq derived binding events for transcription factors (type-B ARABIDOPSIS RESPONSE REGULATORS, ARRs) involved in the cytokinin signalling pathway. Red, blue and green colours depict the peaks from Xie et al., 2018, Zubo et al., 2017 and O'Malley et al., 2016, respectively. The coordinates are represented relative to the transcription start site marked by the arrow. The arrowheads indicate the 5'-end of each promoter as used in (I.) this publication and (II). Pacifici et al., 2018. 
bioRxiv preprint doi: https://doi org/10.1101/2020.06.25.170969; this version posted July 31, 2020. The copyright holder for this preprint (which was not certified by peer review) is the author/funder, who has granted bioRxiv a license to display the preprint in perpetuity. It is made available under aCC-BY-NC-ND 4.0 International license.

\section{pEXPA10::EXPA10:mCherry (fixed cells) + calcofluor white (CFW)}

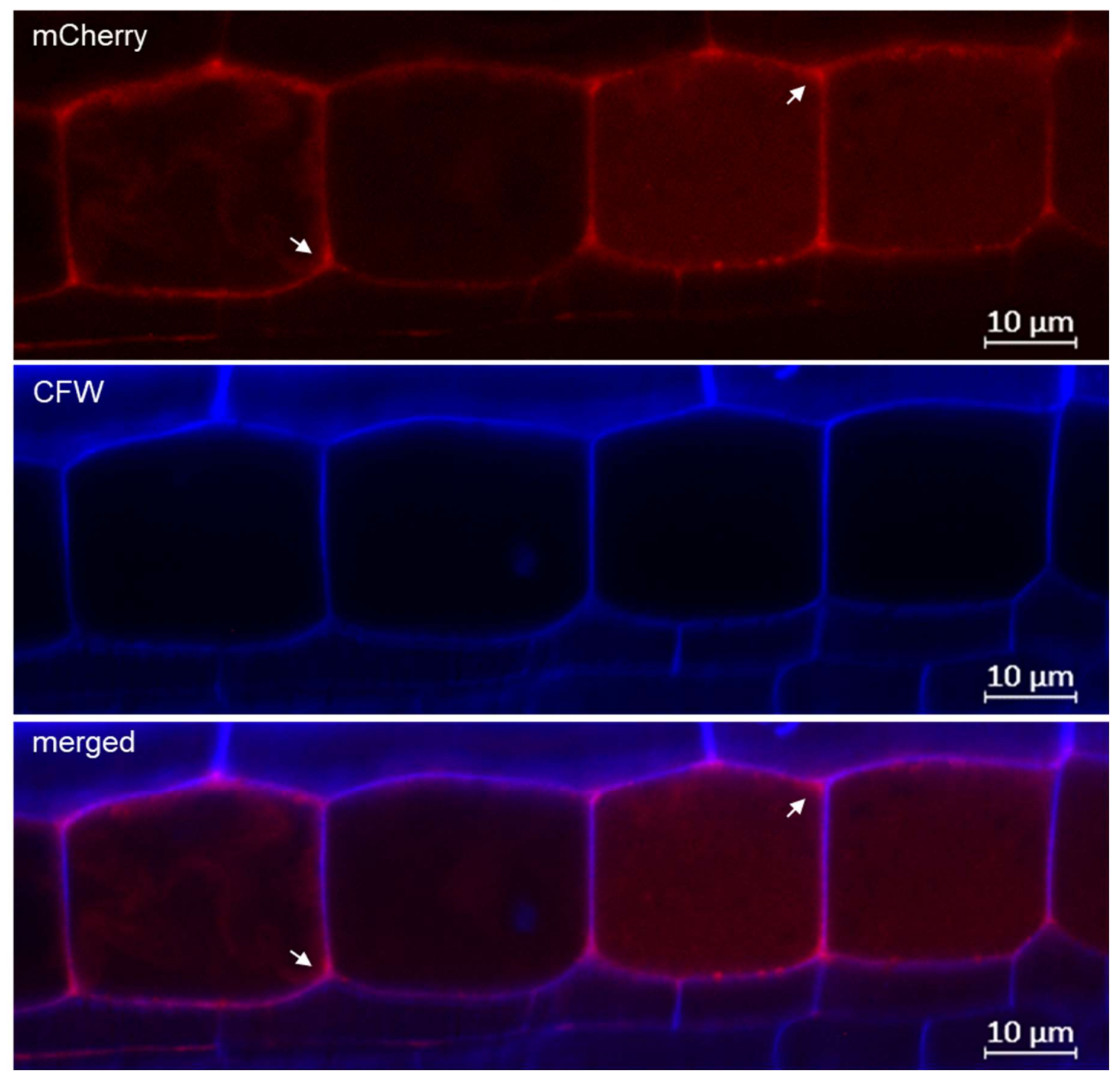

Figure 3 - Figure Supplement 1: EXPA10 does not completely colocalize with cellulose in fixed cell walls.

Z-stack projections of a pEXPA10::EXPA10:mCherry line (red) fixed, cleared and stained with calcofluor white (CFW, blue) according to a protocol in Ursache et al., 2018. The arrowheads point to positions where the EXPA10:mCherry does not co-localise with cellulose deposition as labelled by CFW. Scale bar $10 \mu \mathrm{m}$. 


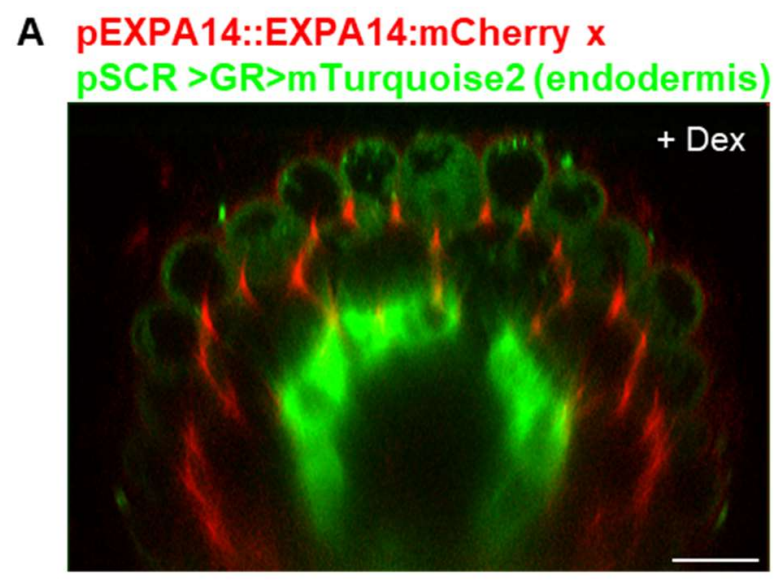

B pEXPA15::EXPA15:mCherry $x$ pSMXL5 > GR>mTurquoise2 (phloem)

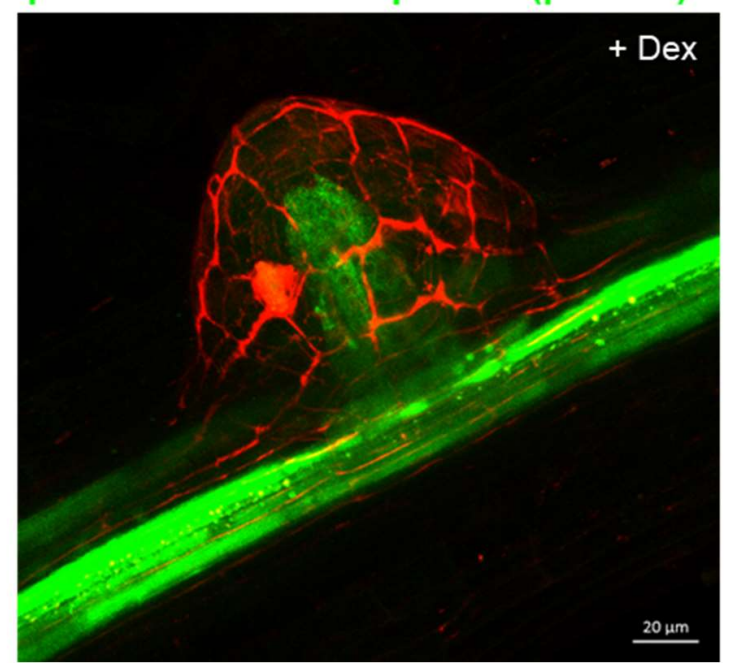

Figure 3 - Figure Supplement 2: Cell-type specific localization of EXPA14 and EXPA15.

(A) Double hemizygous F1 progeny of a cross between pEXPA14::EXPA14:mCherry and endodermis-specific $p S C R>G R>m$ Turquoise2 (Schurholz et al., 2018). In the transversal $(x z)$ optical section of a primary root, the EXPA14 (red) localizes to cortex, endodermis and background autofluorescence in epidermis is in green. (B) Double hemizygous F1 progeny of a cross between pEXPA15::EXPA15:mCherry and phloem-specific $p S M X L 5>G R>m T$ Trquoise2 (Schurholz et al., 2018)In the z-stack projection of an emerging lateral root EXPA15 (red) localizes to the CW of epidermis, phloem is in green. The 7-day old Arabidopsis seedlings were grown on MS media +Dex to induce the mTurquoise2 ER-specific expression. Scale bars correspond to 20 $\mu \mathrm{m}$. 
bioRxiv preprint doi: https://doi.org/10.1101/2020.06.25.170969; this version posted July 31, 2020. The copyright holder for this preprin (which was not certified by peer review) is the author/funder, who has granted bioRxiv a license to display the preprint in perpetuity. It is made available under aCC-BY-NC-ND 4.0 International license.
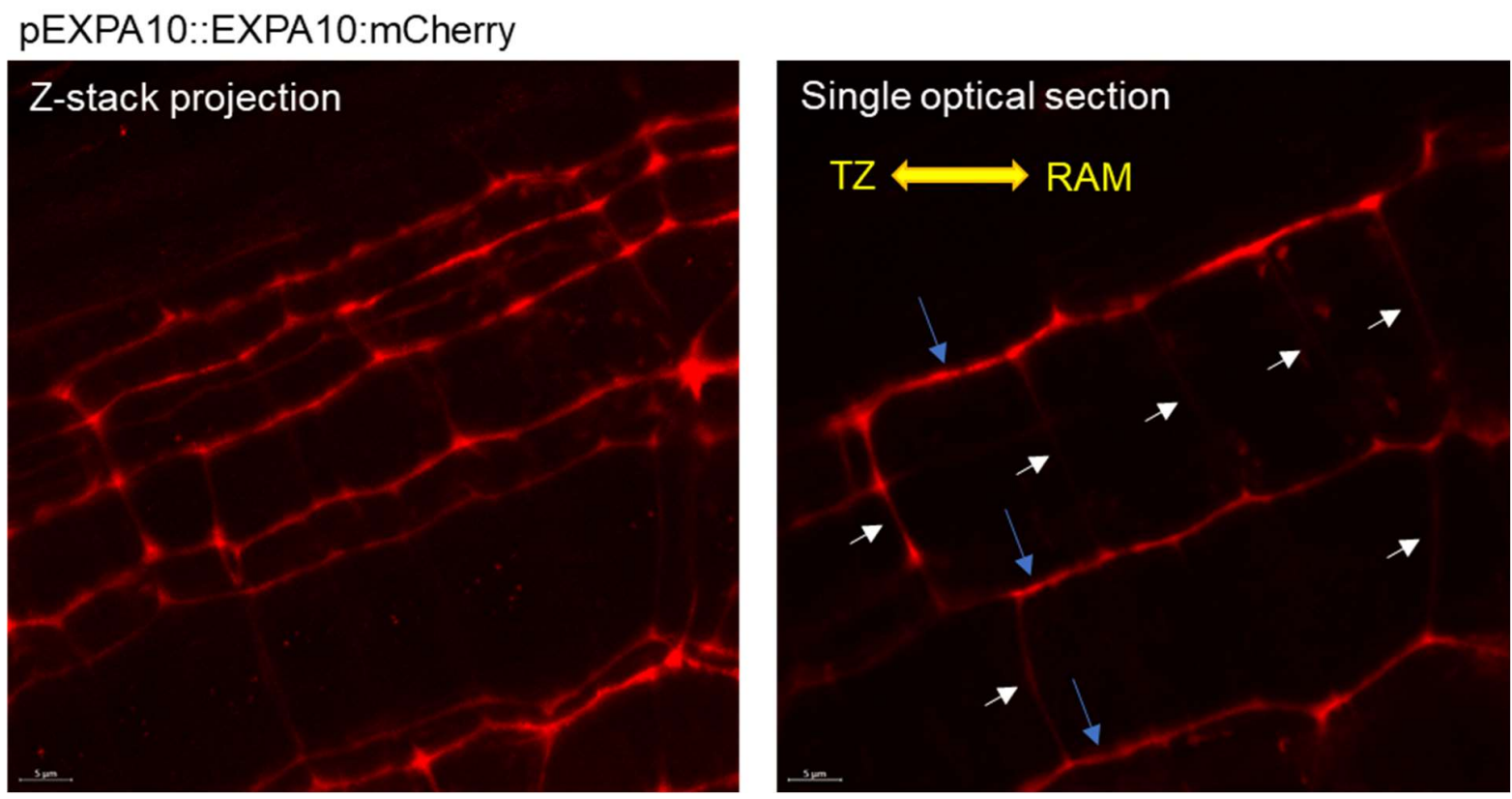

Figure 3 - Figure Supplement 3: EXPA10 localizes predominantly to the longitudinal cell walls.

A z-stack projection (, left) and a single optical section (right) of a 7-day old Arabidopsis root of pEXPA10::EXPA10:mCherry line imagined using the Airyscan detector of Zeiss 880 CLSM. Blue arrows point to longitudinal while white arrows to (less visible due to lower EXPA10 signal intensity) transversal CWs of individual cells; the root orientation is indicated by the yellow double arrows. Scale bar $5 \mu \mathrm{m}$.

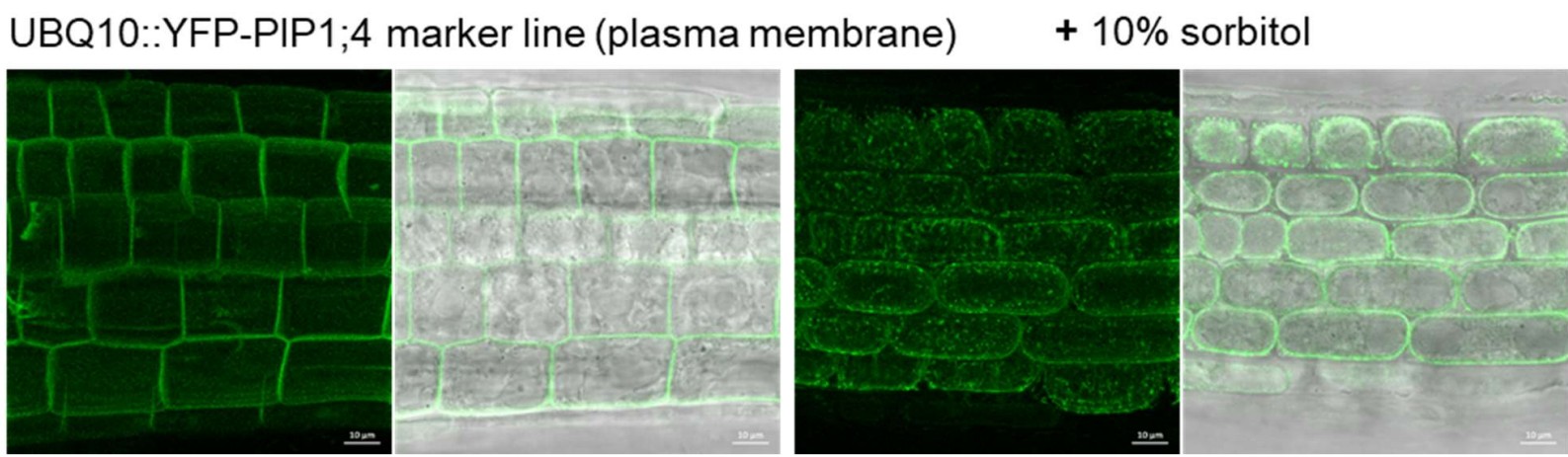

Figure 4 - Figure Supplement 1: Confocal imaging of a plasma membrane marker line UBQ10::YFP-PIP1;4 before and after plasmolysis.

Z-stack projections and transmitted-light micrographs shown as a single optical section of 7-day old Arabidopsis seedlings of a UBQ10::YFP-PIP1;4 line (von Wangenheim et al., 2016) labelling plasma membrane imaged before and after treatment with $10 \%$ sorbitol for $10 \mathrm{~min}$. Scale bar 10 $\mu \mathrm{m}$. 


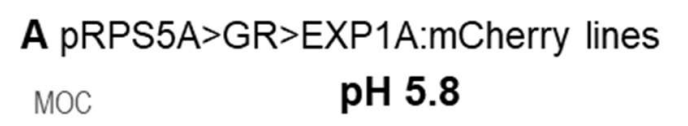

B pRPS5A>GR>EXP1A:mCherry lines
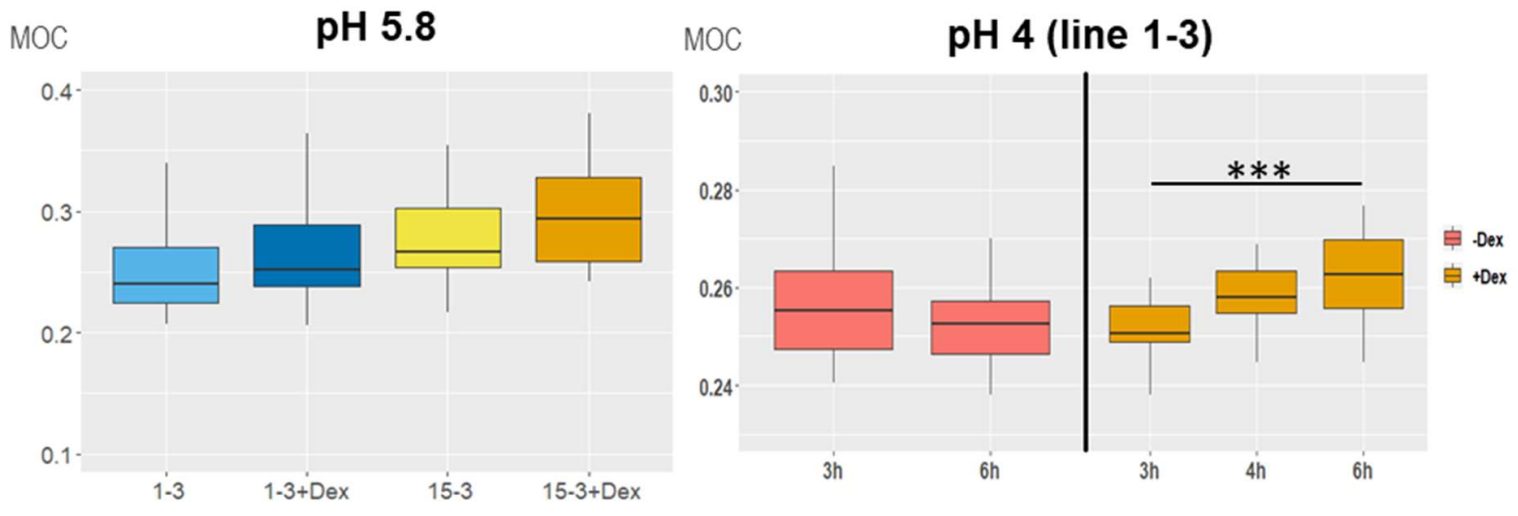

Figure 5 - Figure Supplement 1: Low-level EXP1A:mCherry overexpression reveals only weak cell wall stiffening determined using Brillouin light scattering microscopy.

Mechano-Optical Contrast (MOC) was determined in roots of 7-day old Arabidopsis EXPA1:mCherry overexpressing seedlings pRPS5A>GR>EXPA1:mCherry (lines 1-3 and 15-3) grown on MS media (A) +/- Dex pH 5.8 or (B) induced in liquid MS media pH 4 for $3 \mathrm{~h}-6 \mathrm{~h}$; DMSO was used in -Dex treatments. Medians shown are from at least 4 seedlings and 10 measurements in each category. Statistically significant differences at alpha $0.001\left(^{* * *}\right)$ are shown.

\section{A pRPS5A>GR>EXP1A:mCherry lines}

B $p R P S 5 A>G R>E X P 1 A: m C h e r r y ~ l i n e s$
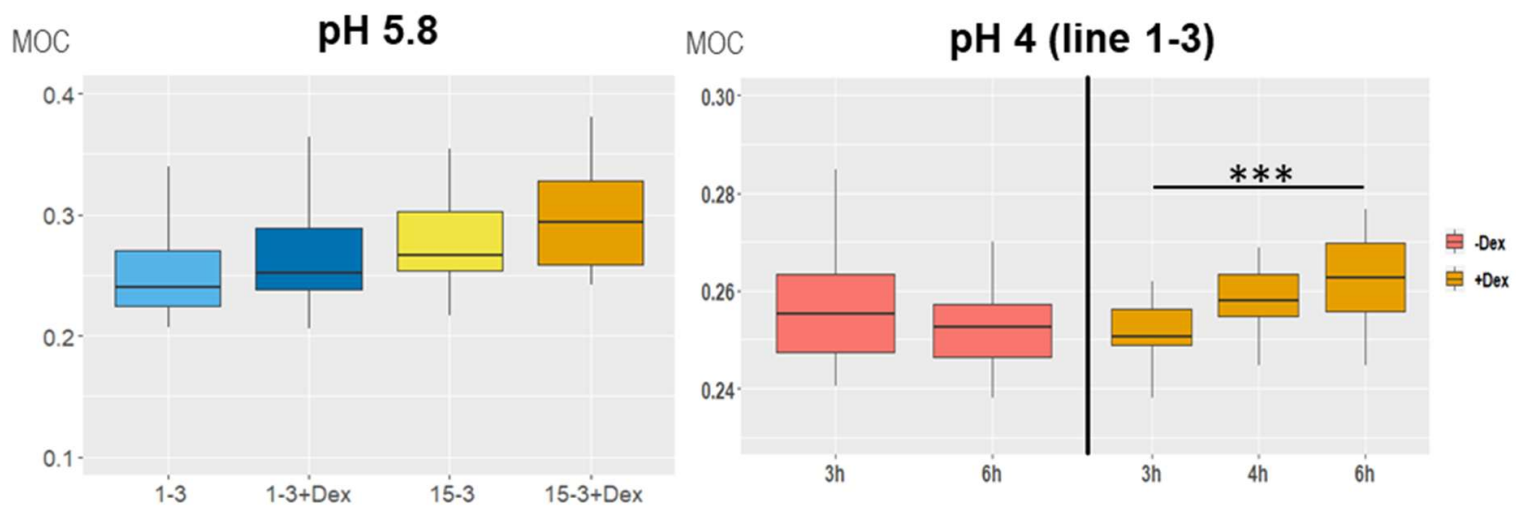

Figure 5 - Figure Supplement 2: Quantitative real-time PCR of Dex-induced levels of expression of EXP1A:mCherry and EXPA1 in selected lines.

Relative EXPA1 expression levels in independent single-copy T3 homozygous lines of (A) pRPS5A>GR>EXP1A:mCherry (1-3, 3-2, 9-1, 15-3, 16-1 and 18-1) and (B) pRPS5A>GR>EXP1A (4-1, 5-4, 6-3, 8-4, 12-4 and 17-1) seedlings grown on MS media +/- Dex for 7 days. The transcript abundance of EXPA1 is double normalized to UBQ10 and WT controls. The experiment was done once with 3 technical replicas. Note the logarithmic scale of the EXPA1 relative expression. 


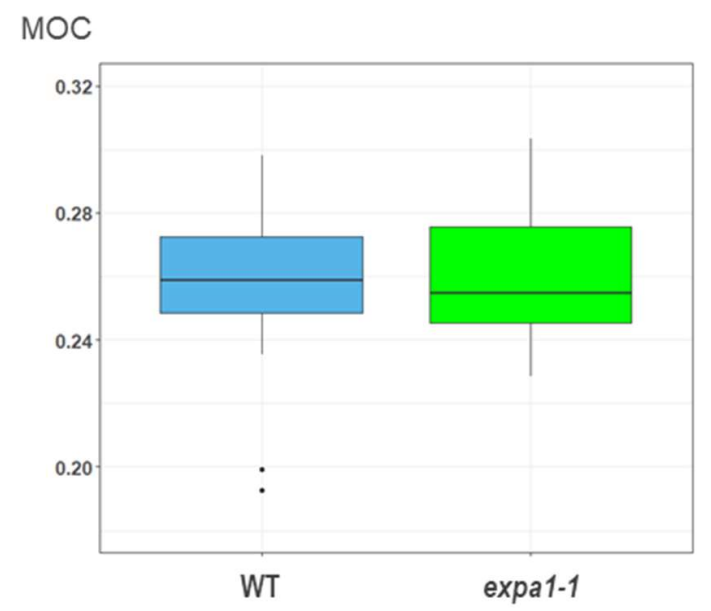

Figure 5 - Figure Supplement 3: Knock-out expa1-1 does not show changes in cell wall stiffening in the TZ determined using Brillouin light scattering microscopy.

Mechano-Optical Contrast (MOC) was determined in roots of 7-day old Arabidopsis WT and expa1-1 knock-out line. Medians shown are from at least 4 seedlings and 12 measurements in each category. There are no statistically significant differences.

A expa1 lines

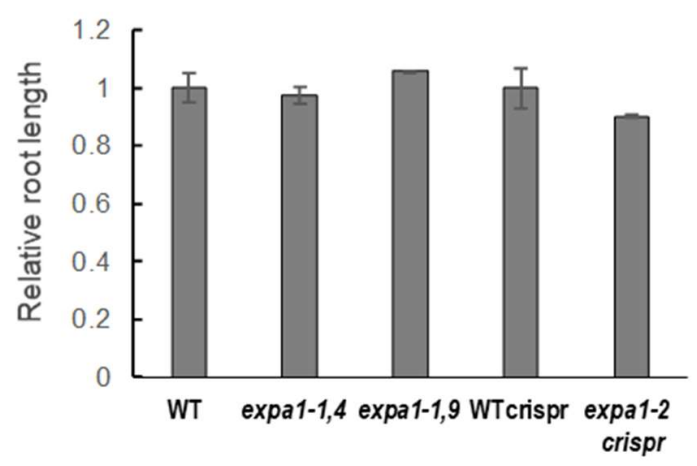

C amiEX1 lines

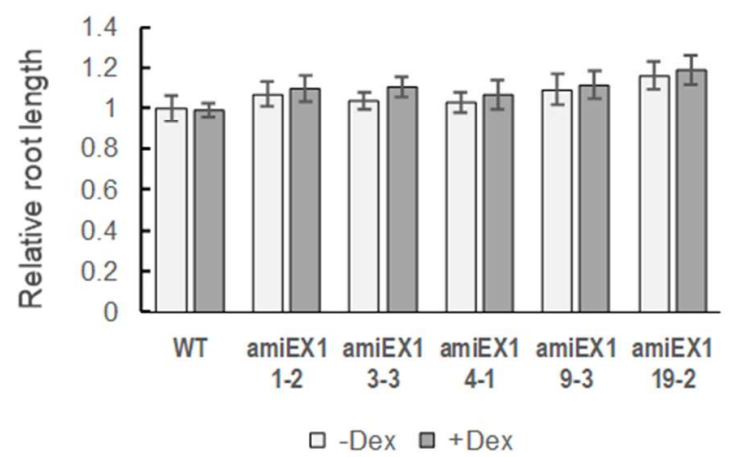

B expa1 lines

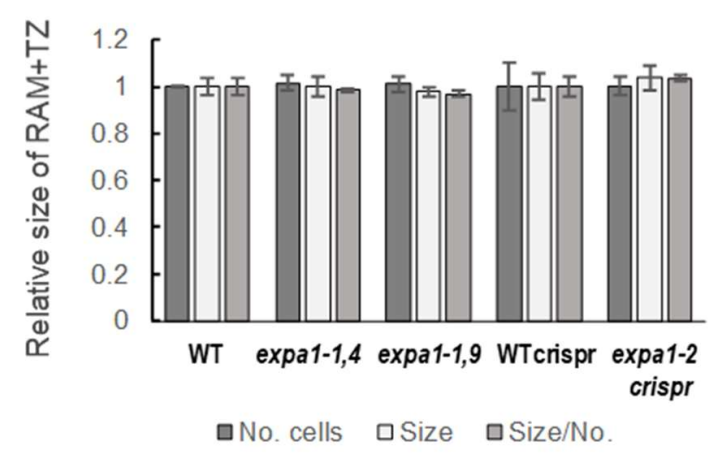

D amiEX1 lines

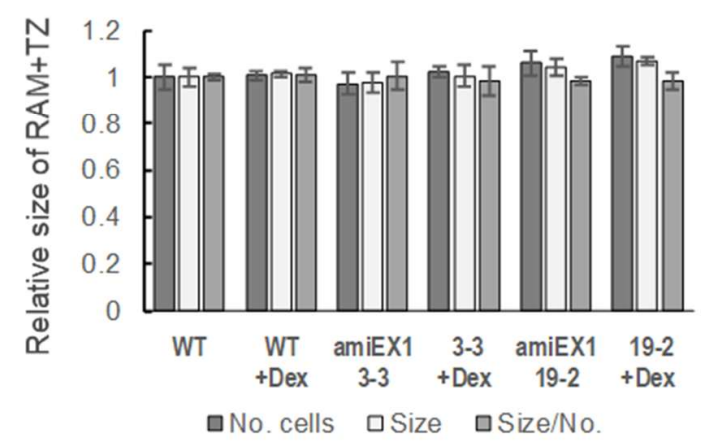


Figure 9 - Figure Supplement 1: Root growth is not affected in expa1 knock-out and EXPA knock-down lines.

(A) Root length and (B) a number of cells in RAM + TZ, size of RAM + TZ size and the ratio size/ number of cells was measured in 7-day old Arabidopsis WT, two families of homozygous knockout lines expa1-1,4 and expa1-1,9 (Pacifici et al., 2018), CRISPR/Cas9 expa1-2 (Ramakrishna et al., 2019) and its null segregant WT control (WT crispr). (C) Root length and (D) a number of cells in RAM + TZ, size of RAM + TZ and the ratio size/ number of cells was measured in WT and selected independent T3 homozygous p35S>GR>amiRNA EXPA1, 14, 15 (amiEX1) lines (1-2, 33, 4-1, 9-3, 19-3) grown on MS media +/- Dex for 7 days. The data are normalised to the corresponding WT, or WT with mock DMSO treatment (-Dex). The experiment was repeated twice with minimum of 10 seedlings in each category, error bars represent standard error of mean. There are no statistically significant differences.

\section{SUPPLEMENTARY MATERIALS AND METHODS}

\section{Plasmolysis experiment}

Arabidopsis seedlings of a plasma membrane marker PM-YFP pUBQ10::YFP-PIP1;4 (von Wangenheim et al., 2016) were immersed into $10 \%$ solution of sorbitol for cca $10 \mathrm{~min}$.

\section{EXPA1 mutant lines}

Knock-out plants of EXPA1 were obtained from the Nottingham Arabidopsis Stock Centre collection (SALK_010506). Homozygous mutant lines from the Salk T-DNA were identified by PCR as described (http://signal.salk.edu/) in the next generation of seedlings and designated as exp11,4 and exp1-1,9. A second mutant line exp1-2 generated using the CRISPR/Cas9 and its corresponding WT (WT crispr) was a gift from Alexis Maizel (Ramakrishna et al., 2019).

AmiEX1 lines based on artificial microRNAs (amiRNAs, miR319a) were designed using the WMD3 Web MicroRNA Designer (WeigelWorld.org) and the PHANTOM database of family targeting amiRNAs (Hauser et al., 2013). The amiRNA sequence engineered for EXPA1 (At1g69530) as well as expansins EXPA14 (At5g56320) and EXPA15 (At2g03090) is "TGTTACACCAACCTGCGGCGT". We used primers I-IV summarised in Supp. Table 1 to generate PCR fragments that were joined together by overlapping PCR using pRS300 vector as a template (see WeigelWorld.org for details). The final product was cloned into the Dex-inducible pOp6/LhGR vector pOpOn2.1 (Craft et al., 2005; Samalova et al., 2019) using primers V and VI and GATAWAYTM cloning strategy. Seedlings of selected T3 homozygous lines were used in the experiments.

Supp. Table1: Primes used for cloning of amiEX1 (p35S>GR>amiRNA EXPA1, 14, 15)

\begin{tabular}{|l|l|l|}
\hline Name & No. & Sequence $\left(\mathbf{5}^{\prime} \mathbf{-} \mathbf{3}^{\prime} \mathbf{)}\right.$ \\
\hline miR-s & I & gaTGTTACACCAACCTGCGGCGTtctctcttttgtattcc \\
\hline miR-a & II & gaACGCCGCAGGTTGGTGTAACAtcaaagagaatcaatga \\
\hline miR $^{*}$ s & III & gaACACCGCAGGTTGCTGTAACTtcacaggtcgtgatatg \\
\hline
\end{tabular}




\begin{tabular}{|l|l|l|}
\hline miR*a & IV & gaAGTTACAGCAACCTGCGGTGTtctacatatatattcct \\
\hline $\begin{array}{l}\text { attB1-EcoRI- } \\
\text { amiRNA-F }\end{array}$ & V & $\begin{array}{l}\text { GGGGACAAGTTTGTACAAAAAAGCAGGCTTCGAATTCCTGC } \\
\text { AGCCCcaaacacacgctcgg }\end{array}$ \\
\hline $\begin{array}{l}\text { attB2-BamH- } \\
\text { amiRNA-R }\end{array}$ & VI & $\begin{array}{l}\text { GGGGACCACTTTGTACAAGAAAGCTGGGTCGGATCCCCCca } \\
\text { tggcgatgcc }\end{array}$ \\
\hline
\end{tabular}

\section{SUPPLEMENTARY REFERENCES}

Craft, J., Samalova, M., Baroux, C., Townley, H., Martinez, A., Jepson, I., Tsiantis, M. and Moore, I. (2005) New pOp/LhG4 vectors for stringent glucocorticoid-dependent transgene expression in Arabidopsis. Plant J 41: 899-918.

Hauser, F., Chen, W., Deinlein, U., Chang, K., Ossowski, S., Fitz, J., Hannon, G.J., and Schroeder, J.I. (2013) A genomic-scale artificial microRNA library as a tool to investigate the functionally redundant gene space in Arabidopsis. Plant Cell 25: 2848-2863.

Pacifici, E., Di Mambro, R., Dello loio, R., Costantino, P. and Sabatini, S. (2018) Acidic cell elongation drives cell differentiation in the Arabidopsis root. EMBO J 37: e99134.

Ramakrishna, P., Ruiz Duarte, P., Rance, G.A., Schubert, M., Vordermaier, V., Dai Vue, L., Murphy, E., Vilches Barro, A., Swarup, K., Moirangthema, K., Jørgenseni, B., van de Cotte, B., Goh, T., Lin, Z., Voss, U., Beeckman, T., Bennett, M.J., Gevaert, K., Maizel, A. and De Smet, I. (2019) EXPANSIN A1-mediated radial swelling of pericycle cells positions anticlinal cell divisions during lateral root initiation. Proc Natl Acad Sci 116: 8597-8602.

Samalova, M., Kirchhelle, C. and Moore, I. (2019) Universal methods for transgene induction using the dexamethasone-inducible transcription activation system pOp6/LhGR in Arabidopsis and other plant species. Current Protocols in Plant Biol 4: e20089.

Schurholz, A.-K., Lopez-Salmeron, V., Li, Z., Forner, J., Wenzl, C., Gaillochet, C., Augustin, S., Vilches Barro, A., Fuchs, M., Gebert, M., Vermeer, J. E. M., Lohmann, J. U., Greb, T. and Wolf, S. (2018) A comprehensive tool set for inducible, cell type-specific, gene expression in Arabidopsis. Plant Physiol, 178: 40-53.

Ursache, R., Andersen, T.G., Marhavy, P. and Geldner, N. (2018) A protocol for combining fluorescent proteins with histological stains for diverse cell wall components. Plant J 93: 399-412.

Von Wangenheim, D., Fangerau, J., Schmitz, A., Smith, R.S., Leitte, H., Stelzer, E.H. and Maizel, A. (2016) Rules and self-organizing properties of post-embryonic plant organ cell division patterns. Curr Biol 26: 439-49. 